\title{
FINAL REPORT OF THE UMTRA INDEPENDENT TECHNICAL REVIEW of TAC AUdit PRograms
}

\section{October 1994}

\section{DISCLAIMER}

This report was prepared as an account of work sponsored by an agency of the United States Government. Neither the United States Government nor any agency thereof, nor any of their employees, makes any warranty, express or implied, or assumes any legal liability or responsibility for the accuracy, completeness, or usefulness of any information, apparatus, product, or process disclosed, or represents that its use would not infringe privately owned rights. Reference herein to any specific commercial product, process, or service by trade name, trademark, manufacturer, or otherwise does not necessarily constitute or imply its endorsement, recommendation, or favoring by the United States Government or any agency thereof. The views and opinions of authors expressed herein do not necessarily state or reflect those of the United States Government or any agency thereof. 
This report has been reproduced from the best available copy.

Number of pages in this report: 89

For availability contact:

Office of Scientific and Technical Information

P.O. Box 62

Oak Ridge, TN 37831

(615) 576-8401

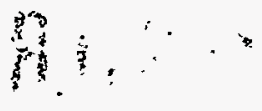




\section{DISCLAIMER}

Portions of this document may be illegible in electronic image products. Images are produced from the best available original document. 
FINAL REPORT OF THE

\section{UMTRA INDEPENDENT TECHNICAL REVIEW OF TAC AUDIT PROGRAMS}

\section{Technical Reviewers:}

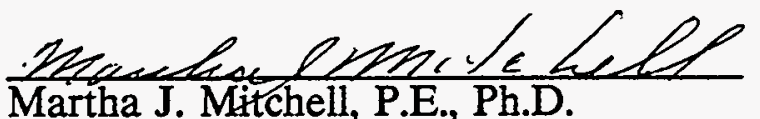

Roy F. Weston, Inc.

Albuquerque, New Mexico

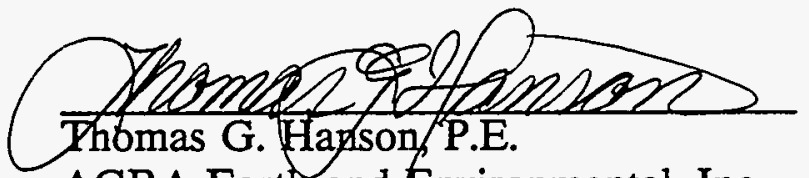

AGRA Earth and Environmental, Inc.

Kirkland, Washington
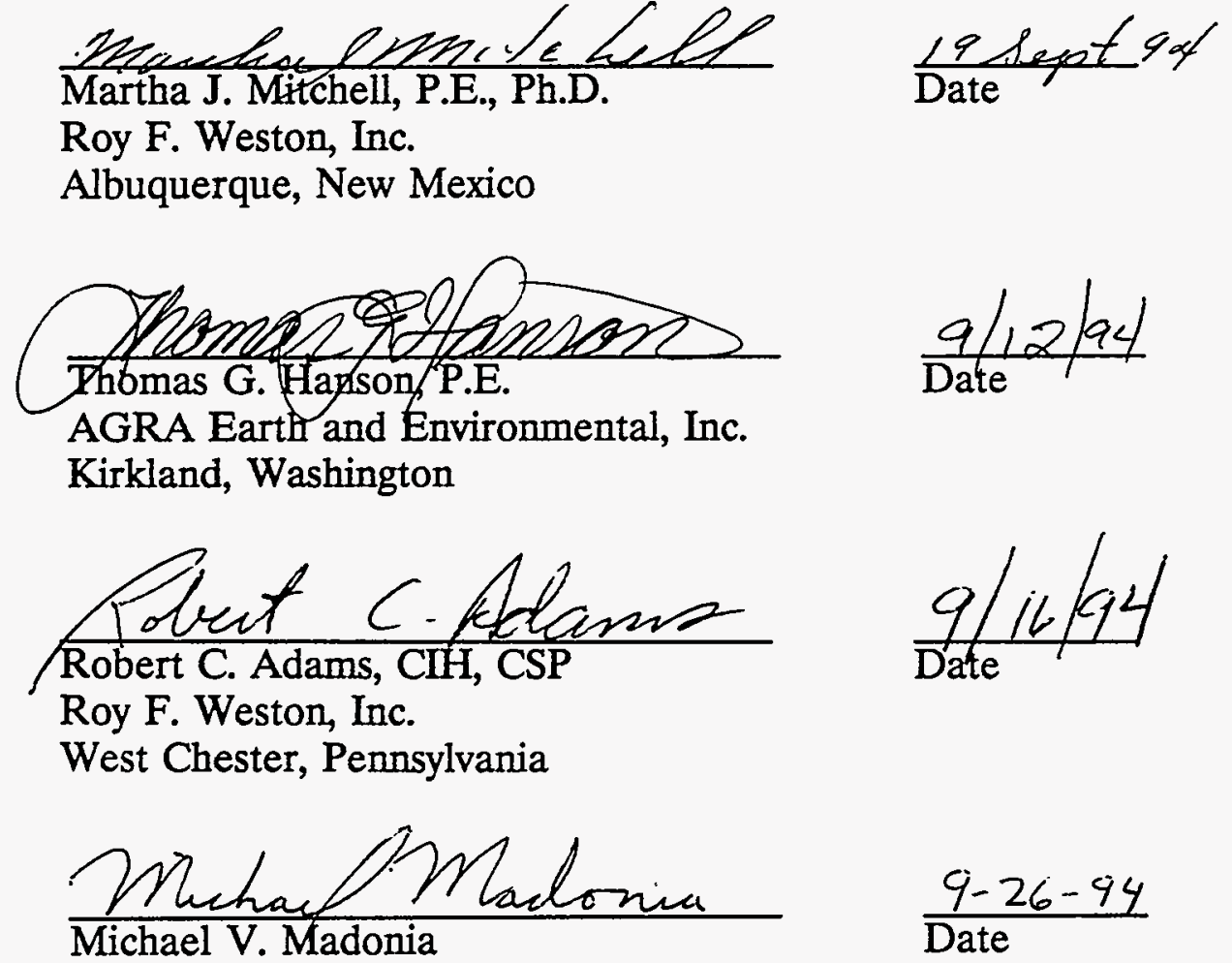

Roy F. Weston, Inc.

Albuquerque, New Mexico

$$
\frac{9-26-94}{\text { Date }}
$$


Prepared for U.S. Department of Energy UMTRA Project Office Albuquerque, New Mexico

\section{Prepared by} Jacobs Engineering Group Inc. Albuquerque, New Mexico 


\section{EXECUTIVE SUMMARY}

This report details the findings of an Independent Technical Review (ITR) of practices and procedures for the Uranium Mill Tailings Remedial Action (UMTRA) Project audit program. The audit program is conducted by Jacobs Engineering Group Inc., the Technical Assistance Contractor (TAC) for the U.S. Department of Energy (DOE) UMTRA Project. The purpose of the ITR was to ensure that the TAC audit program is effective and is conducted efficiently.

The ITR was conducted from May 16-20, 1994. A review team observed audit practices in the field (at Rifle, Colorado, and Mexican Hat, Utah), reviewed the TAC audit program's documentation, and discussed the program with TAC staff and management at the Jacobs Engineering Group's UMTRA Project Office in Albuquerque, New Mexico.

This Level I ITR was conducted in accordance with the UMTRA Project Independent Technical Review Implementation Plan. Level I ITRs are conducted by TAC corporate specialists and require DOE notification and approval. The technical reviewers were:

\section{Technical reviewer}

Martha Mitchell, Ph.D, P.E.

Thomas Hanson, P.E.

Robert Adams, CIH, CSP

Michael Madonia
Company

WESTON

\section{Area reviewed}

Quality assurance and geotechnical testing

AGRA Earth and Environmental, Environmental Inc. WESTON Health and safety

WESTON Radiological

Appendix A contains a copy of a letter from Roger A. Nelson of Jacobs to Al Chernoff of the DOE dated February 21,1994 . It defines the task to be performed by the ITR team and provides management's approval for it. The scheduling of the ITR depended solely on the scheduling of the field audits.

Responses to the specific questions the review team addressed are summarized here; Section 8.0 contains a complete response for each type of audit.

a. Are the TAC organizational responsibilities for audits clearly defined? Is consistency of approach demonstrated throughout the Project?

While TAC policies, plans, and procedures define the responsibilities of TAC personnel for audit programs reasonably well, those responsibilities are not always executed as defined because the TAC's audit documentation is not integrated with the responsibilities of the DOE and the Remedial Action Contractor (RAC), Morrison Knudsen-Ferguson (MK-F) Company. There does not appear to be a consistent audit approach across the types of audits performed. 
b. What value are the TAC audit programs adding to the UMTRA Project? Have trending and root cause analysis been performed?

Their primary value appears to be to add to the level of readiness of site personnel. The current programs do not add nearly as much value to the UMTRA Project as they should. Limited informal trending is performed; no root cause analysis is performed.

c. What changes should be made to the programs to increase their value?

Recommendations are made for each type of audit, beginning on page 8-3.

d. How is the information from audits used and by whom?

The audit reports are primarily used by the RAC to correct site-specific problems and physical deficiencies found in specific operations. Little other use has been made of them.

e. What areas are not being audited that should be? What areas are being audited that shouldn't be?

Generally, the scopes of the TAC audits do not include programmatic issues and management systems. Overlaps with RAC internal audits should be carefully considered and managed. Audit frequency and scope need to be reconsidered.

f. How are staff chosen for audit teams? Are the audit staff qualification requirements adequate? How do team members stay current with their field?

Staff members are chosen based primarily on their qualifications and experience. Their relationships with those being audited have not been a deciding factor in staff selection. Audit staff qualification requirements appear adequate for the types and levels of audits being performed; however, these requirements should be reviewed should programmatic issue and management system audits be added to audit scopes. A wide variety of methods for staying current in the auditors' fields were apparent.

\section{Organization of the report}

On July 9, 1986, the U.S. Environmental Protection Agency (EPA) issued its final policy statement on environmental auditing. The statement identifies a model for an effective environmental auditing program; the elements of this model are recognized by the ITR team as important aspects of any auditing program. Based on this EPA policy statement, the ITR team adopted the following set of criteria to evaluate the TAC's audit programs:

- Management commitment.

- Assignment of responsibilities.

- Qualifications and objectivity of auditors.

- Audit program objectives.

- Program implementation.

- Audit reporting and corrective actions. 
The format of this report has been developed around these components; they comprise most of the major section headings. Each section begins by identifying the criteria that the TAC program is measured against, then describing the approach used by the ITR team to measure each TAC audit program against the criteria. An assessment of each type of audit is then summarized for each component in the following order:

- Radiological audit summary.

- Health and safety audit summary.

- Environmental audit summary.

- Quality assurance audit summary.

Section 8.0 provides responses to each question identified under the scope of work for each type of audit. Appendix B contains the full text of the July 9, 1986, EPA Environmental Auditing Policy Statement. References consulted and reviewed during the course of this ITR are found in Appendix C. 


\section{TABLE OF CONTENTS}

$\underline{\text { Section }}$

1.0 AUDIT CATEGORIES, PROCESSES, AND PERSONNEL $\ldots \ldots \ldots \ldots \ldots \ldots$

1.1 Radiological audits . . . . . . . . . . . . . . . . . 1-1

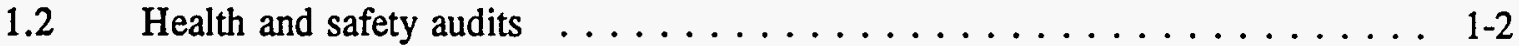

$1.3 \quad$ Environmental audits . . . . . . . . . . . . . . . . . 1-2

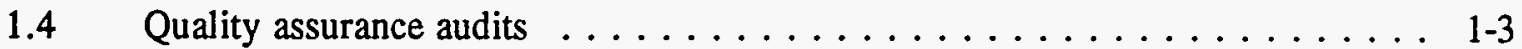

2.0 MANAGEMENT COMMTMENT $\ldots \ldots \ldots \ldots \ldots \ldots \ldots \ldots \ldots \ldots \ldots$

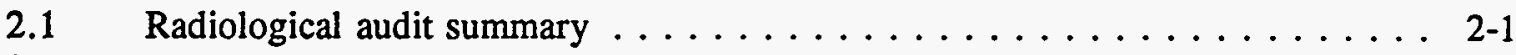

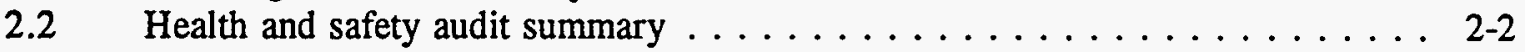

2.3 Environmental audit summary . . . . . . . . . . . . . 2-2

2.4 Quality assurance audit summary ................. 2-3

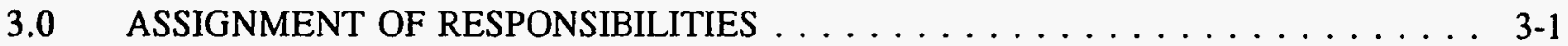

3.1 Radiological audit summary . . . . . . . . . . . . . . . . 3-1

$3.2 \quad$ Health and safety audit summary . . . . . . . . . . . . . . . $3-2$

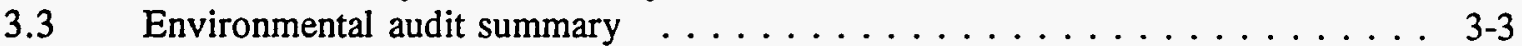

3.4 Quality assurance audit summary ................... 3-3

4.0 QUALIFICATIONS AND OBJECTIVITY OF AUDITORS $\ldots \ldots \ldots \ldots \ldots$

$4.1 \quad$ Radiological audit summary . . . . . . . . . . . . . . . . . . 4-1

$4.2 \quad$ Health and safety audit summary . . . . . . . . . . . . . . . 4-2

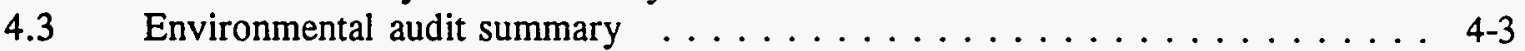

4.4 Quality assurance audit summary . . . . . . . . . . . . . 4-4

$5.0 \quad$ AUDIT PROGRAM OBJECTIVES $\ldots \ldots \ldots \ldots \ldots \ldots \ldots \ldots \ldots$

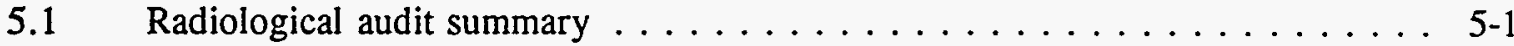

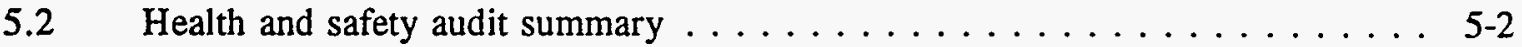

5.3 Environmental audit summary . . . . . . . . . . . . . 5-2

5.4 Quality assurance audit summary . . . . . . . . . . . . . . . 5-4

6.0 PROGRAM IMPLEMENTATION $\ldots \ldots \ldots \ldots \ldots \ldots \ldots \ldots \ldots \ldots$

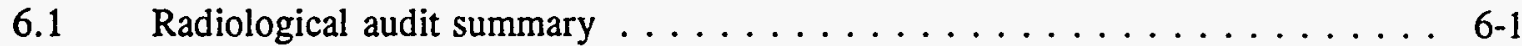

6.2 Health and safety audit summary . . . . . . . . . . . . . . . . . 6-2

6.3 Environmental audit summary ... . . . . . . . . . . . . . . . . 6-4

6.4 Quality assurance audit summary . . . . . . . . . . . . 6-5

7.0 AUDIT REPORTING AND CORRECTIVE ACTIONS $\ldots \ldots \ldots \ldots \ldots \ldots \ldots$

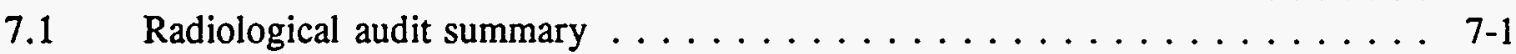

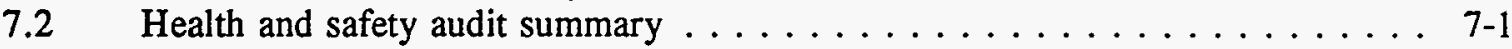

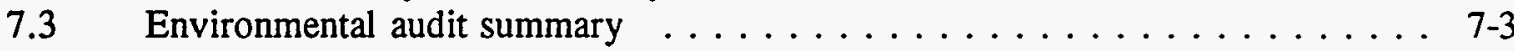

7.4 Quality assurance audit summary . . . . . . . . . . . . 7-3

8.0 RESPONSES TO QUESTIONS $\ldots \ldots \ldots \ldots \ldots \ldots \ldots \ldots \ldots \ldots$ 
TABLE OF CONTENTS (Concluded)

$\underline{\text { Section }}$

$\underline{\text { Page }}$

$9.0 \quad$ REFERENCES $\ldots \ldots \ldots \ldots \ldots \ldots \ldots \ldots \ldots \ldots \ldots \ldots \ldots \ldots \ldots \ldots$

APPENDIX A SCOPE OF WORK FOR INDEPENDENT TECHNICAL REVIEW OF

TAC AUDIT PROCEDURES

APPENDIX B ENVIRONMENTAL PROTECTION AGENCY

ENVIRONMENTAL AUDITING POLICY STATEMENT

APPENDIX C BIBLIOGRAPHY 


\section{LIST OF ACRONYMS}

\section{Acronvm}

AADITS
DOE
DQO
EPA
H\&S
ITR
LRA
MK-F
NRC
ORE
ORR
OSHA
QA
QAPP
QC
RAC
SAFE
SPCC
TAC
UMTRA

\section{Definition}

Assessment and Analysis Documentation and Information Tracking System U.S. Department of Energy data quality objective U.S. Environmental Protection Agency health and safety Independent Technical Review lead radiological auditor Morrison Knudsen-Ferguson U.S. Nuclear Regulatory Commission operational readiness evaluation operational readiness review Occupational Safety and Health Administration quality assurance Quality Assurance Program Plan quality control

Remedial Action Contractor Safety Advancement Field Effort spill prevention and containment control Technical Assistance Contractor Uranium Mill Tailings Remedial Action 


\subsection{AUDIT CATEGORIES, PROCESSES, AND PERSONNEL}

\subsection{RADIOLOGICAL AUDITS}

Technical Assistance Contractor (TAC) responsibilities for radiological audits of Remedial Action Contractor (RAC) activities are described in the TAC Management Plan (DOE, 1993a), Guidelines for Conducting Radiological Surveillances of Remedial Action Activities at UMTRA Processing Sites (DOE, 1988a), and Albuquerque Operations Manual (JEG, n.d.) (TAC audit procedure 10.7.1). These documents and historical audit observations and findings formed the basis for selecting audit checklist topics.

The TAC Regulatory Compliance Department manager and auditors discuss these audit areas in preparation for the field audit. The radiological audit completion process requires that the auditors return to Albuquerque after the site closeout meeting to investigate the basis for potential observations and findings. A draft audit report is then submitted to the TAC Regulatory Compliance Department manager for review. The TAC Regulatory Compliance Department manager forwards the draft audit report to the DOE for review, and a final audit report incorporating DOE comments is prepared.

The DOE transmits the final radiological audit report to the RAC for comment and response, and the RAC response is returned to DOE and the TAC. The TAC evaluates the RAC's comments and recommends to DOE whether each finding or observation should be closed or remain open pending additional evaluation. TAC management and auditors stated that the time associated with this transmittal process was excessive, and that certain observations and findings could be obscured or dropped through the review and preparation cycle.

Primary radiological audit activities were observed at the Rifle, Colorado, site on May 16-17, 1994. The TAC lead radiological auditor (LRA) was Jim Hylko; he was assisted by trainee Martin Brennan. Robert Fencil was the RAC site health physics manager. The TAC audit team was well prepared; it had an audit procedure and five checklists to implement previously determined audit technical areas. The Department of Energy (DOE) was represented by Frank Bosiljevac and Bennett Young. The usual DOE representative for the radiological portion of audits, Robert Cornish, was unable to attend the Rifle audit.

Additional information was obtained during a Mexican Hat, Utah, site visit on May 18-19. No radiological audit was performed at Mexican Hat during this period; however, the RAC site health physics manager, Phil Mohrmon, was interviewed.

Management perspective was assessed during a visit to the TAC Albuquerque Office on May 19. Interviewees with primary knowledge and involvement in the radiological audit process included Linda Ulland (the Regulatory Compliance Department manager) and Mark Miller (deputy assistant project manager for the Technical Services Department). 


\subsection{HEALTH AND SAFETY AUDITS}

The TAC responsibilities for health and safety (H\&S) audits of the RAC are described in the TAC Management Plan (DOE, 1993a), UMTRA Project Environmental Health and Safety Plan (DOE, 1992), and UMTRA Project Audit/Surveillance Program Plan (DOE, 1988b). In Section 2.2 of the UMTRA Project Audit/Surveillance Program Plan, the following statement establishes the TAC charge for the audit program:

"The TAC is charged with the responsibility of overseeing this program. The primary function of the TAC's health and safety program is not a simple verification of the contractor's safety plan but a verification that the safety plans are comprehensive and are being applied."

An H\&S field audit consists principally of a thorough site walkthrough and inspection for objective evidence, a records review, and a closeout meeting. The TAC auditors prepare a draft final audit report within 10 days of the site visit and submit it to the DOE Project Office for review; DOE forwards a copy of the draft final report to the RAC for review and response, and a date for review is set at that time. When the review is completed, the TAC auditors complete a final audit report within 10 days. The final report is transmitted to the DOE Project Office, which transmits it to the RAC within 5 days. The time required to complete this process is more than 1 month, with additional time needed for the report to be received by site management.

Primary H\&S audit activities were observed at the Rifle site on May 16-17, 1994. The TAC lead auditor was Larry Ross, who was assisted by Fred Shelly. The managers for the RAC were Jim Roeder (the RAC H\&S manager) and Lon Baldwin from the MK-F Albuquerque Office. Representing the DOE were Bennett Young and Frank Bosiljevac.

The TAC auditors did not have any audit protocols in their possession. They did have audit checklists and copies of previous audits.

Additional information was obtained during the May 18-19 Mexican Hat site visit. While no H\&S audits were conducted during this visit, interviews with Bart Jones and Pat Hayden, site safety representatives, and Tim Swisse, site manager, were conducted. Anh Nguyen was the DOE representative interviewed.

Management perspective was assessed during discussions at the TAC Albuquerque Office on May 19. Three persons familiar with the TAC H\&S audits were interviewed: Linda Ulland, the Regulatory Compliance Department manager; Jim Gibb, the assistant project manager for the Technical Services Department; and Mark Miller, the deputy assistant project manager for Technical Services.

\subsection{ENVIRONMENTAL AUDITS}

Preliminary evaluation of the TAC environmental audit program began May 16 with interviews of DOE and RAC managers involved in the TAC audit programs. These interviews, which continued through May 17, were used to gain an initial understanding 
of management elements identified as important to each TAC audit program. The individuals interviewed were Frank Bosiljevac and Bennett Young of the DOE and Lon Baldwin, Jim Roeder, and Scott Bunney of MK-F.

The primary environmental audit process was observed at the Mexican Hat site May 18-19. The lead environmental auditor at Mexican Hat was Teri Monaghan, who was assisted by Malu Gawthrop-Cooper. During this audit, Ms. Monaghan and Ms. Gawthrop-Cooper were also interviewed. Finally, the TAC management group responsible for the audit program was interviewed by the Independent Technical Review (ITR) team in Albuquerque on May 19. These individuals were Jim Gibb, Mark Miller, Linda Ulland, and Ray Bennett (the Quality Assurance Department manager).

\subsection{QUALITY ASSURANCE AUDITS}

Quality assurance (QA) audits are mainly records-oriented and function top-down from requirements to implementation. For the $\mathrm{QA}$ audit program review, the following approach was used:

1. Identify the QA requirements that affect the generic QA audit function.

2. Identify the consistency with which these requirements are reflected in QA planning documents and the geotechnical controls influencing the activities that were observed during the audits.

3. Evaluate the implementing procedures for the QA audits (including those potentially associated with the audit activities and those associated with activities that are usually included in full-scope QA audits), and the technical activities identified as geotechnical in nature.

4. Review QA audit-related documents and records and the corrective action, follow-up, and closeout processes for effectiveness and for compliance with upper-tier requirements and plans. The records required a thorough evaluation, since a sample of only one QA audit was observed during this ITR.

5. Interview audit organization staff and management members of the RAC, QA auditors associated with both the DOE and TAC, and management representing the DOE (as available) and the TAC in particular.

6. Evaluate QA staff qualifications and auditor/lead auditor qualifications and training.

7. Determine whether QA audits meet requirements and other needs and whether they are effective.

8. Use informal checklists as guides for the observation and interviews.

The final actions were interviews of the QA staff at the Rifle site on May 16-17, and observation of the audit conducted at the Mexican Hat site on May 18-19. 


\subsection{MANAGEMENT COMMITMENT}

CRITERIA Has management demonstrated the necessary degree of commitment to foster the efficient and effective implementation of the TAC audit program? Has management commitment been communicated to all levels involved in environmental protection programs?

APPROACH Interview DOE, TAC, and RAC managers assigned responsibility for oversight of audit and corrective action programs to assess their awareness of and support for these programs. Interview TAC auditors and RAC site personnel to determine whether management commitment has been communicated to those responsible for implementing these programs.

Review past audits and corrective action schedules to verify that audit findings have been closed promptly. If any corrective actions have not been completed by their scheduled closure dates, confirm that schedule changes were reviewed and approved by the appropriate levels of DOE, TAC, and RAC management.

Review program documentation to verify that the program is supported by a written policy articulating upper management support, which includes an explicit written commitment to follow up on audit findings.

\subsection{RADIOLOGICAL AUDIT SUMMARY}

The TAC auditors stated that adequate management commitment is received in the preparatory phase of radiological audits. A written audit procedure exists in addition to a letter to the TAC Regulatory Compliance Department manager specifying the technical areas of the audit. The LRA believed that existing TAC management had excellent auditing credentials on the Uranium Mill Tailings Remedial Action (UMTRA) Project and other projects, and that the managers were a good reference source to answer questions before, during, and after audits.

\section{Conclusions}

Management commitment is communicated within the TAC radiological process through routine involvement in the preparation and review phases of the audit. TAC management stated that no consistent upper-level written (or verbal) policy on management involvement or commitment was available. The findings and observations resulting from the audit and implementation of corrective actions are reviewed and approved by appropriate levels of DOE, TAC, and RAC management. The review process is sometimes performed over a period of several months.

\section{Recommendation}

The management roles and responsibilities among UMTRA Project participants should be clearly defined and added to programmatic plans, including the TAC Management Plan and the Quality Assurance Program Plan (QAPP). 


\subsection{HEALTH AND SAFETY AUDIT SUMMARY}

The overall commitment to an audit process has been communicated to responsible persons within the TAC organization. The documents reviewed do not establish a commitment to a specific type of audit desired by the DOE, a defined scope of work, or general expectations.

Ownership of H\&S audits belongs to the DOE. Draft DOE UMTRA Project Office ES\&H Quality Assurance Guidelines (DOE, 1994), provided by Bennett Young during the Rifle, Colorado, site visit, establish that the "DOE UMTRA Project Office has selected the TAC Regulatory Compliance Department to coordinate the UMTRA auditing program." The UMTRA Project Audit/Surveillance Program Plan (DOE, 1988b) states that "The TAC has the responsibility for performing four types of appraisals for the U.S. Department of Energy .... (emphasis added). This ownership was reported, nearly unanimously, during interviews. The TAC is responsible for conducting the RAC audits, with the DOE setting the level of commitment to the audit process. Audit functions have been delegated to the TAC, such as developing the written documents that establish the basic audit process. The DOE has the authority to approve and implement the audit process established by the TAC.

\section{Conclusion}

TAC management, with DOE approval, needs to define and establish a commitment to a specific audit type, based on specific goals and objectives to be obtained from the TAC audits. The commitment must spell out structures, protocols, and guidelines for the H\&S audit process that define the direction the audit teams should take.

TAC management is currently committed to a process that more closely resembles an inspection than an audit. This has led to a greater emphasis on finding objective evidence of physical hazards, with a reduced emphasis on management or programmatic issues.

\section{Recommendation}

TAC management needs to commit to an audit process that has a defined scope, mission, goals, and objectives. The commitment must define the direction, guidelines, and protocols for the audit team to be effective. It is recommended that a "management system" audit be the principal type of audit rather than comprehensive compliance audits or needs assessment audits. (Refer to Section 6.2 for a description of H\&S audit types.)

\subsection{ENVIRONMENTAL AUDIT SUMMARY}

Responsible managers in the DOE, TAC, and RAC voiced support for each TAC audit program, and their support was evident during the ITR.

In general, the UMTRA Project may pose fewer serious environmental risks than other DOE activities. However, other federal activities are generally able to apply more resources to environmental compliance and risk management, commensurate with the risks posed by these activities. In addition, operations at the UMTRA Project sites are in most 
respects comparable to the regulated operations of private industry. These regulated operations and the environmental requirements imposed on them are viewed by private industry and the regulatory agencies as both significant and substantial. In fact, the complexity of the environmental requirements imposed on industry, and the significant penalties that can result from noncompliance, may be credited with the development of private sector auditing over the last decade.

\section{Conclusions}

Downplaying the importance of any of the TAC audit programs may undermine the effectiveness of these programs. UMTRA program and project managers who have determined or who have been led to believe that environmental compliance is secondary may also place less emphasis on environmental audit findings. Indeed, audited site managers may perceive identified noncompliance as less serious than the repercussions of an audit finding, and so may resist both the identification of noncompliance and the development of findings. Where this resistance is allowed to affect the outcome of the audit, the audit program is diminished, in some cases to a point where the audit program can no longer be relied upon to provide an objective measure of compliance.

\section{Recommendation}

To ensure that all UMTRA Project participants fully implement and support the TAC audit programs, especially the environmental audit program, TAC management should request that the DOE UMTRA Project Office issue a written policy statement articulating its support of these audit programs and committing DOE, RAC, and TAC personnel to a joint, cooperative effort to identify and resolve both actual and potential noncompliance.

\subsection{QUALITY ASSURANCE AUDIT SUMMARY}

Based on interviews of management and nonmanagement individuals associated with the UMTRA Project in DOE, the TAC, and the RAC, there is awareness and commitment to providing quality products and services associated with project activities. The QA audit function and its purpose is better understood at management than at nonmanagement levels. Some confusion and uncertainty was apparent in responses to questions such as "Who owns the QA independent audit process?" and "What are the differences between DOE and TAC audits?"

During this evaluation, one of the most valuable activities undertaken was a discussion of methods used to construct layers of material covering uranium mill tailings in the cell. The concern was that building a subsequent layer would damage previously compacted material. The DOE/TAC audit team and the RAC QA staff discussed these methods and observed the construction tests. The RAC QA staff appeared comfortable and familiar with this level of involvement in technical decisions.

These activities were recorded in a RAC staff notebook. Records such as these are important and should provide information of interest to other sites, both now and in the future. The TAC should formally document these records and give them greater visibility. 
DOE Order 5700.6C cites U.S. Environmental Protection Agency (EPA) guidance documents that apply to environmental protection and/or remediation, including EPA 540, "Data Quality Objectives for Remedial Response Activities," and EPA 530, "Technical Guidance Document: Construction QA for Land Disposal Facilities." This indicates that these documents are to be taken as general guidance and are applicable beyond EPA-regulated activities.

In the QA planning documents evaluated during this assessment, no EPA QA requirements or guidelines are recognized as providing methods for implementing these EPA or environmental requirements. Documents such as EPA Quality Assurance Management Staff 005/80, "Interim Guidelines and Specifications for Preparing Quality Assurance Project Plans," and EPA/530-SW-86-031, "Technical Guidance Document Construction For Hazardous Waste Land Disposal Facilities," provide information on implementing QA principles in environmental activities. Data quality objectives (DQO) are not in general use. The DQO process identifies readily usable performance indicators for tracking and trending.

Section 10.5.1 of the UMTRA Project Office Quality Assurance Program Plan (DOE, 1993b) states "An audit notification letter for announced audits shall be provided by the UMTRA Project Office QA Manager or [Technical Services Group leader] to the organization being audited 2 weeks before the audit starts." Contrary to this, the QA audit activity assigned for observation as part of this assessment was dated May 13; the activity start date was May 18. It should be determined whether the UMTRA Project Office Quality Assurance Program Plan includes requirements or makes commitments that are not within the responsibility of the TAC.

Based on field interviews and observations, assigned staff resources for the activities identified as QA audits appear to be sufficient. These resources should be reevaluated if the scope of these evaluations change from in-process QA surveillances to QA audits (refer to the QA audit summary in Section 3.0).

Section 10.11 of the UMTRA Project Office Quality Assurance Program Plan (DOE, 1993b) states that the "Project Office shall evaluate the Project contractor's independent assessment systems through verification techniques such as audits, in-process surveillances, and reviews . . . ." Currently, no such activities are identified on the audit schedule.

The audit information does not appear to be sufficiently useful to the staff of either the TAC or the site. This is supported by the findings in Sections 3.0 and 7.0 of this report. The commitment to quality activities is present. Full implementation appears to be an area where additional evaluation is needed. The audit team used the audit process to solve problems in a rather unconventional, but necessary, way. 


\subsection{ASSIGNMENT OF RESPONSIBILITIES}

CRITERIA Are organizational responsibilities for the audit program, including audit program development and implementation, corrective actions, and program reviews, clearly defined? Do audit procedures reflect the defined organizational responsibilities?

APPROACH Review program documentation to determine how responsibilities have been assigned, and to whom.

Interview DOE, TAC, and RAC personnel to confirm that the responsibilities assigned by the program documentation have been adopted by the assigned organizations and personnel.

Review audit procedures to confirm that they reflect the organizational responsibilities defined in the program documentation.

\subsection{RADIOLOGICAL AUDIT SUMMARY}

TAC radiological program auditor responsibilities are defined in the radiological audit procedure (JEG, n.d) (Section 10.7.1). The procedure refers to a variety of technical audit areas covered in detail in audit checklists. TAC management responsibilities with respect to the RAC and DOE are not written.

The TAC Regulatory Compliance Department manager played an adequate role in coordinating radiological audit teams. The lead auditor recognized the organizational structure of the audit process within the UMTRA program. The auditors recognized that they had sufficient latitude to investigate areas outside those defined in the audit scope letter and checklists. This was the case during the radiological audit at the Rifle site, where the auditor trainee was allowed to investigate processes and records beyond the defined audit scope.

The TAC managers stated that they were sometimes not certain of DOE responsibilities with respect to the audit and that higher-tier program plans contained vague or oblique definitions.

\section{Conclusions}

Responsibilities for the TAC auditors are defined in the radiological audit procedure (JEG, n.d.) (Section 10.7.1). This procedure was last updated in March 1993. The Regulatory Compliance Department manager could provide more management insight to the usefulness of audits through more intensive review and periodic modification of the radiological audit procedure. Because TAC management responsibilities with respect to the RAC and DOE are not written, they are subject to interpretation. 


\section{Recommendation}

These issues can be addressed through preparation of a clear, consistent policy statement in all applicable UMTRA Project programmatic documents.

\subsection{HEALTH AND SAFETY AUDIT SUMMARY}

The UMTRA Project Audit/Surveillance Program Plan (DOE, 1988b), "Functional Responsibilities," and the TAC Management Plan (DOE, 1993a), "Audit Activities," assign the responsibility for conducting H\&S audits to the TAC. The TAC Management Plan states that ". . . health and safety staff of the TAC regulatory compliance department routinely conducts health and safety audits of RAC construction activities . .." The TAC Management Plan, however, is not specific with regard to organizational responsibilities for the audit process in the H\&S field.

Documentation of the specific responsibility for developing the audit program or procedures was not presented. The TAC auditors indicated in interviews that program and procedure development has been assumed as a TAC function but without definite guidelines or protocols established. DOE management reported that formal procedures were not adopted at this time. No identification of responsible parties for developing formal procedures was available. It was estimated that it would take about 1 year to develop formal audit protocols.

Documentation of the assigned responsibility for developing corrective action plans was not presented. The RAC has been developing corrective action plans based on the findings of TAC audits. The plans are submitted to the TAC for review. Disagreements are mediated by the DOE; this responsibility is written in the DOE UMTRA Project Office ES\&H Quality Assurance Guidelines (DOE, 1994), an unpublished document (refer to Section 6.2).

During the daily debriefing at Rifle, DOE management assumed the responsibility for deciding what constitutes an H\&S finding. Again, no documentation of who is responsible for verifying findings based on the objective evidence was available to the ITR team members.

\section{Conclusions}

There are no clear assignments of responsibility among the Project participants for the . $H \& S$ audits. While documentation delegates the overall responsibility for H\&S audits to the TAC, the DOE assumes responsibility for some elements of the audit process.

\section{Recommendations}

Assignments of responsibility for TAC H\&S audits should be clearly established. The documentation needs to specify who the responsible parties are and what elements of the audit process they are responsible for. It is particularly important to assign responsibilities to avoid overlap of activities during TAC audits. Written responsibilities 
will help ensure that TAC, RAC, and DOE managers understand where the responsibility for specific audit activities resides and will help avoid conflicts and disagreements.

\subsection{ENVIRONMENTAL AUDIT SUMMARY}

Written policies, plans, and procedures clearly define the responsibilities of TAC personnel for TAC audit programs. During the audits at the Rifle site, DOE personnel revealed to the ITR team an informal audit procedure that was being used by DOE staff and TAC auditors to guide audit activities. This draft procedure has not been reconciled with the existing TAC procedures.

Ultimately, the DOE is responsible for determining whether corrective actions to address TAC audit findings are needed and whether actions proposed by the RAC are sufficient. To make effective decisions, the DOE must be assured that the information provided by the audits is objective and unbiased. This assurance is provided by auditors whose status and organizational assignments support "objective and unobstructed inquiry, observation and testing," and who are not subject to any "interference with free inquiry or judgment, or fear of potential retribution" (51 FR 25004 (1986)).

\section{Recommendation}

The responsibilities of Project participants with respect to audits should be agreed to and clearly defined in writing.

\subsection{QUALITY ASSURANCE AUDIT SUMMARY}

Based on interviews with TAC and RAC staff and a review of documents (including the QA plans from both DOE and the TAC), the requirements for a $\mathrm{QA}$ audit are contained in a number of planning documents and procedures. These documents are "owned" by both the DOE and the TAC. As a result, there is uncertainty concerning audit roles and responsibilities and some requirements for completing an audit as described in the planning documents and procedures. The document hierarchy does not appear to show appropriate flowdown of requirements or to be structured to the UMTRA Project organizational structure. Few requirements for the preparation phase of an audit are identified in the QA planning and the scope of the material to be audited. A letter of notification for the audit/surveillance activity provides the reference or source documents but not what is usually identified as a scope.

It appears that opening meetings are carried out at a different level of formality at different sites. This may result from individual differences among staff members at the two sites or it may result from different attitudes concerning the audit function. A more formal approach to audit opening appears to allow for better coordination of the audit activities and helps the audit team maintain a more structured approach. 


\subsection{QUALIFICATIONS AND OBJECTIVITY OF AUDITORS}

CRITERIA Do the individuals assigned to perform audits possess the necessary level of understanding of applicable standards and requirements, and of how those standards and requirements are generally applied? Do systems exist for informing auditors of changes to the applicable standards and requirements? Has a system been established for confirming the qualifications of auditors prior to their assignment to an audit? Have auditors been screened for personal or professional relationships that could impair the auditor's objectivity or create a conflict of interest? Are auditors encouraged to pursue relevant inquiry unobstructed?

APPROACH Review the qualifications and training records of individual auditors to determine their level of experience and expertise.

Interview selected auditors to confirm their understanding of pertinent regulations and standards and the applicability of these regulations and standards to RAC activities. Determine through these interviews and from training records the means used to inform auditors of changes to applicable standards and requirements.

Determine whether procedures have been established to screen auditors for potential conflicts of interest.

Confirm through interviews that audit staff are encouraged to pursue relevant inquiry without obstruction.

\subsection{RADIOLOGICAL AUDIT SUMMARY}

The LRA had significant audit experience on the UMTRA Project and in auditing privatesector facilities. His technical background was more than adequate to assess the technical objectives and procedures of the RAC and to assess changing regulatory conditions potentially affecting the Project. The LRA had attended formal auditor training and has published a variety of papers on QA as it relates to auditing. Technical exchanges with other auditors attending these conferences are used to exchange ideas and practices; this allows the LRA to remain current in the technical audit subject areas.

The trainee had no UMTRA Project audit experience but significant private-industry experience that was demonstrated through the audit process. He made several technical observations beyond the defined scope of the audit.

Auditor credentials are reviewed by the Regulatory Compliance Department manager, and it is necessary that a lead auditor have performed at least five audits within the past 3 years. No formal system of documenting the changes to current standards and requirements exists. Auditors are charged to stay current in these areas, and the Regulatory Compliance Department manager transmits information as received in the form of memos. 


\section{Conclusions}

The LRA had outstanding qualifications and training to prepare and perform the audit. He had a good relationship with the RAC site health physics manager; this relationship gave him ready access to the files and individuals necessary to complete the audit. On the other hand, the LRA might not be as inclined to pursue potential observations and findings outside the primary audit technical areas. However, the health physics site manager has an extensive U.S. Nuclear Regulatory Commission (NRC) background, and the Rifle site has had an excellent history regarding minor observations and findings. In addition, the radiological audit program is mature enough so that field activities are audited against specific requirements, and site personnel know what is expected. This also demonstrates that the radiological audit program works effectively.

Complete objectivity may not be attainable in the radiological audit programs. The radiological protection/health physics field is a relatively small community, and experienced professionals frequently cross paths during their careers. The subset of professionals with uranium mining, milling, and tailings experience is even smaller. An experienced auditor may be predisposed to individuals believed and acknowledged to be more (or less) competent. With two experienced UMTRA Project auditors having a knowledge of site history and an understanding of critical areas related to site closure, two additional auditors will prevent repetition and ensure an effective radiological audit program.

\section{Recommendations}

The participation of a technically experienced individual new to the UMTRA Project (the trainee) was productive to the audit process and should be formalized as a requirement in the radiological audit procedure. There is a distinct advantage in having at least one auditor on the team who is not acquainted personally with the RAC staff. Since two audits are scheduled per year at each UMTRA Project site, it is advisable that the same individual not act as LRA on both audits. This person may participate as an assistant but should refrain from developing too close a relationship with the RAC staff and site health physics manager. These criteria could be added to the radiological audit procedure (JEG, n.d.) (Section 10.7.1).

\subsection{HEALTH AND SAFETY AUDIT SUMMARY}

Auditors who are unbiased and independent and have freedom of inquiry are key to the objectivity of UMTRA Project audits. Audit team members should not have a stake in the outcome of the audit and should not show favoritism or bias in their auditing efforts. The auditors must be free to pursue avenues of inquiry as appropriate, based on the objective evidence found during the audits (AIHA, 1994).

A system must exist for UMTRA Project auditors to remain current with standards, regulations, and DOE orders. The auditors must also be provided with opportunities to pursue professional development. Systems need to be in place to monitor the training and professional development of the auditors. 
The TAC currently has two H\&S auditors. Both possess experience in construction safety and industrial hygiene. One is a Certified Safety Professional. The other is both a Certified Safety Professional and a Certified Industrial Hygienist. The resumes of both show that they have had prior auditing experience.

During the daily closeout meeting at Rifle, it was observed that a DOE representative was making the determination of the findings based on the objective evidence the TAC auditors presented. However, the DOE representative had not accompanied the TAC auditors for any substantial portion of the audit. The TAC auditors are in a better position to make these determinations based on their superior knowledge of the objective evidence.

The TAC has a system in place to track and monitor training and professional development of TAC personnel, including the TAC auditors.

\section{Conclusions}

Both current TAC auditors possess the appropriate level of experience to carry out the functions of the audit teams of the TAC audits. Both have an objective point of view and are independent.

\section{Recommendations}

The process for determining findings based on objective evidence needs to be reconciled by TAC management and incorporated in the TAC procedures.

\subsection{ENVIRONMENTAL AUDIT SUMMARY}

It appears that the TAC has attempted to retain qualified individuals to staff the TAC audit programs and to keep those individuals abreast of applicable requirements and standards. The individuals currently involved in environmental audits each possess more than 5 years of experience in environmental compliance activities; both had ready access to such needed tools as the Federal Register and the Bureau of National Affairs Environment Reporter. Yet, the skills that distinguish a successful auditor have not been clearly defined by the regulatory agencies; they seem to require a combination of regulatory knowledge, understanding of audit techniques and approaches, and familiarity with industrial plant operations. Such knowledge and familiarity are not gained through college accreditation, through successful completion of environmental or H\&S training programs, or even through the experience that most environmental professionals acquire during years of environmental practice. Generally, the capabilities of an auditor come largely from experience gained by conducting audits.

\section{Conclusions}

The individuals assigned to perform UMTRA Project environmental audits do not possess the depth of experience in conducting environmental audits required to support an effective environmental auditing program. The TAC audit programs have created mechanisms for overcoming auditor inexperience through a mentorship program; 
however, this program is currently hampered by the relative inexperience of those acting as mentors.

\section{Recommendations}

The mentorship program should continue to receive the support of the DOE and the TAC. The TAC should also make sure that auditors selected in the future possess the necessary mix of regulatory knowledge, understanding of audit techniques and approaches, and familiarity with construction site operations, consistent with audit program objectives.

\subsection{QUALITY ASSURANCE AUDIT SUMMARY}

A primary requirement of the QA audit/assessment function is that the involved personnel have no direct responsibilities for the areas audited. Contrary to this, the assessment personnel participated in construction decisions. It should be noted that these decisions were appropriate and needed.

The interactions between TAC and RAC personnel involved in making decisions demonstrated a high level of communication and problem solving. However, these are not consistent with the independence that should be demonstrated during an audit.

The QA organization, as shown in organization charts, is not separated into technical/QA and audit functions; such separation ensures independence of the audit function and decreases the possibility of an auditor evaluating an activity in which he or she has been overly involved. Auditors do not appear to be selected for an audit based on independence. This organizational approach hinders both the assessment activity and the program development and maintenance activities.

The UMTRA Project program called the Safety Advancement Field Effort (SAFE), as practiced, provides this differentiation in responsibilities and appears to allow technical staff from different organizations to mutually make necessary decisions outside the audit process.

The TAC QA planning document identifies QA staff as specialists, not engineers. No technical requirements or responsibilities are identified, and no technical background is required. The activities included in audits/surveillances are primarily technical. An evaluation of the staffing needs and skills is needed, as is technical training.

According to staff associated with audit activities, on-the-job and project training was mentioned as the way most of the audit training was received. General DOE/EPA QA and quality control (QC) training and external audit training would strengthen the QA and evaluation processes. This is particularly important with the many changes occurring in QA and environmental programs.

The UMTRA Project is complex, as is its document structure. During the audit process, the audit team is responsible for adhering to requirements from multiple documents simultaneously. An evaluation is needed to ensure that training covers requirements from all sources. 
The independence of the audit/evaluation function is critical to the effectiveness of an audit. This independence protects the evaluation from allegations of conflict of interest and allows the auditors to be free from conflicts during the evaluation. Long-term relationships at either the individual or the organizational level decrease actual or perceived independence. When evaluating mature programs, auditors should maintain their objectivity and guard against allowing activities to slip into a state of complacency.

The interorganizational decision-making process is important and should not be lost. This decision-making process deserves more recognition and should be further strengthened. 


\subsection{AUDIT PROGRAM OBJECTIVES}

CRITERIA Is the audit program based on a set of clearly defined objectives? Have these objectives been communicated to the individuals responsible for the audit program, including program managers and audit staff? Has the audit program been structured to achieve these objectives?

APPROACH Through reviews of audit program documentation, audit procedures, and audit reports and through interviews with DOE, TAC, and RAC managers and staff, determine the principal objectives of the audit programs.

Determine whether the audit program managers and staff have a uniform understanding of the audit program objectives.

Verify through document reviews and interviews that audit program elements, including audit staff selection and personnel training programs, have been structured to achieve the audit program objectives.

\subsection{RADIOLOGICAL AUDIT SUMMARY}

At the technical level of audit implementation, TAC auditors and RAC site managers stated that radiological program objectives are clear but that management responsibilities are not. TAC auditors stated that the program objectives were to ensure compliance with current applicable regulations and TAC and RAC procedures. This generally agreed with the tone of the DOE introduction at the Rifle audit opening meeting.

When asked if they believed the audit program objectives were achieved, the TAC auditors and deputy assistant project manager stated that the program objectives had been achieved and could continue to be achieved in the future with less frequent audits, and perhaps through participation in beginning-of-year readiness reviews. RAC site health physics managers were less inclined to believe that these objectives were met through the TAC audit program. The RAC managers believed that internal RAC audits were more effective at identifying potential technical problems and noncompliance issues. The RAC health physics manager stated that internal audit results were not forwarded to the TAC for review. Both the Rifle and Mexican Hat site health physics managers stated that TAC audits did add to the level of readiness of site personnel, which was a positive contribution.

\section{Conclusions}

There is a relatively uniform level of understanding for the radiological audit program objectives among the RAC, TAC, and DOE (both management and auditors). Given the evolution of the radiological audit program, a thorough management assessment should be performed for these objectives. Currently, the RAC health physics managers believe that the TAC radiological audit program yields limited findings and observations that, in general, have little or no impact on the quality of the UMTRA Project radiological 
protection program. However, the TAC identified numerous examples of findings that, when addressed, improved the quality of the radiological program.

\section{Recommendations}

If current audit program objectives are retained, they should be formally stated in UMTRA Project program documents, including the TAC Management Plan and QAPP. However, it is recommended that DOE, TAC, and RAC management meet to determine whether more value would be added to the radiological audit program by modifying objectives to focus more on information transfer and dissemination, rather than a purely technical nuts-and-bolts audit of a mature radiological protection program. The TAC should routinely receive a copy of the RAC audit summaries to avoid unnecessary duplication of effort.

\subsection{HEALTH AND SAFETY AUDIT SUMMARY}

The UMTRA Project Environmental Safety and Health Plan (DOE, 1992) and the UMTRA Project Audit/Surveillance Program Plan (DOE, 1988b) provide general objectives for audits. These are not specific objectives with measurable parameters. RAC and TAC personnel interviewed were not aware of specific audit objectives beyond the general objectives stated in these two documents.

\section{Conclusions}

UMTRA Project audit objectives are not specific, achievable, or measurable. The overall objective of the audits is communicated to RAC and TAC organizations.

\section{Recommendations}

Specific audit objectives need to be established for DOE, TAC, and RAC management and should be related to the specific responsibilities assigned to each organization. The audit objectives must be measurable and achievable.

\subsection{ENVIRONMENTAL AUDIT SUMMARY}

TAC management has not explicitly defined the objectives of the TAC audit program. As a result, individuals in each organization identified different and, in some cases, inconsistent program objectives. Furthermore, since the audit program was not developed to accomplish specific objectives, the program design and staffing are not adequate to accomplish some of the objectives identified by these individuals. For example, environmental audit personnel indicated that the primary objective of their audit was to ensure compliance with applicable regulations, DOE orders, and plant procedures. However, the observed data-gathering activities focused on potential environmental risks, such as potential sources of spills and releases; the audit team appeared to direct little attention to compliance with the administrative and procedural requirements of the applicable regulations, DOE orders, or internal plans or policies. Unfortunately, environmental risks, and particularly risks posed by stored hazardous materials, are not well-regulated, and findings related to environmental risk are often difficult to justify 
based on regulatory requirements. For an environmental audit program to effectively address environmental risks, the audited facility generally needs to accept that an objective of the audit is to identify these risks, and that audit findings will not necessarily be based on promulgated standards.

On the other hand, if the objective of the audit program is to ensure compliance with applicable regulations, each audit should include a thorough review of environmental plans, procedures, and records to verify that they satisfy the regulatory requirements. Each audit should be flexible enough to accommodate enforceable requirements identified in environmental plans prepared by the facility, such as the inspection and training schedules outlined in facility spill prevention and containment control (SPCC) plans. Satisfying this objective demands that audit personnel also stay informed of regulatory developments, including clarifications issued by the regulatory agencies. To date, UMTRA Project environmental audits have not achieved this objective for the following reasons:

- Little attention has been directed to compliance with administrative and procedural requirements.

- The audit program does not highlight requirements that are considered by the regulatory agencies to be fundamental to compliance.

- The auditors have not received guidance on assessing facility training programs.

- The audit program does not sufficiently consider the enforceable provisions of facility environmental plans and procedures.

- The auditors are not well informed of regulatory developments of consequence to UMTRA Project operations.

For example, past audits have not attempted to identify shortcomings of the environmental plans prepared by the RAC.

The ITR team noted that the following specific shortcomings of the Mexican Hat site SPCC plan were not reported in the site environmental audit report:

- While attesting that the SPCC plan had been prepared in accordance with good engineering practices, the professional engineering certification stated only that the engineer had reviewed the plan and was familiar with the provisions of 40 CFR Part 112. Under 40 CFR $\$ 112.3$ (d), ". . . the engineer, having examined the facility and being familiar with the provisions of this part, shall attest that the SPCC plan has been prepared in accordance with good engineering practices." Furthermore, most state regulations governing the practice of professional engineering specify that a registered engineer may affix his or her signature and seal only to plans or documents prepared under his or her direct supervision. Site personnel stated that the SPCC Plan had been prepared by contractor employees. 
- The SPCC plan had not been updated to reflect the relocation of bulk storage tanks from the Monument Valley, Arizona, site to Mexican Hat. According to 40 CFR $\$ 112.5$, owners or operators must amend a facility SPCC plan "whenever there is a change in facility design, construction, operation, or maintenance which materially affects the facility's potential for the discharge of oil into or upon the navigable waters of the United States or adjoining shorelines. Such amendments shall be fully implemented as soon as possible, but not later than six months after such change occurs." The ITR representative did not verify the date on which the tanks were relocated; however, the RAC should be advised of the possible need to update the facility SPCC plan, as stipulated in 40 CFR $\$ 112.5$.

\subsection{QUALITY ASSURANCE AUDIT SUMMARY}

The audit scope at some locations may not include all quality-affecting activities. Grading of the quality activities at each location should be evaluated. This evaluation should include all QA elements; audits should be done of any elements not covered in recent audits.

Risk, grading, and activities not previously included in audits should be stressed in evaluations. Technical performance indicators and categories for trends should be developed for Project use.

The entire QA program needs to be evaluated to determine whether it provides the controls and implementation needed for the activities included in the Project. 


\subsection{PROGRAM IMPLEMENTATION}

CRITERIA Have TAC audit programs incorporated a suitable degree of consistency? Are audit approaches, procedures, and checklists comparable for each programmatic area? Have audit findings and corrective actions in each programmatic area been communicated to comparable levels of management and received the degree of consideration appropriate to their significance? Do the methods used to collect, analyze, and interpret information provide data that are factual, adequate, and convincing; reliable; relevant to the program objectives; and useful in terms of helping the program achieve its goals?

APPROACH Review the TAC audit procedures for selected programmatic areas to confirm that audit programs are implemented with a suitable degree of uniformity.

Determine to what level of management significant audit findings have been reported, and compare the reporting of these findings to the reporting of significant findings in other programs.

Review previous audit reports and interview audit personnel to determine whether information obtained during an audit is sufficient to provide a sound basis for audit findings and recommendations, and whether the information is reliable, relevant, and useful.

\subsection{RADIOLOGICAL AUDIT SUMMARY}

The radiological audit program has evolved over the past 10 years, and $\mathrm{TAC}$ auditors and management agree that the radiological audits are consistent in implementation, documentation, and corrective actions. This interpretation is based on the fact that the frequency of major findings or recommendations (those affecting the integrity or efficiency of radiological measurements, excavation control, etc.) has decreased continuously over the life of the audit program.

Auditors consistently review previous audit reports and supplemental technical information to provide a basis for preparing future audit plan subject areas. The LRA stated that he had received formal Assessment and Analysis Documentation and Information Tracking System (AADITS) training in February, but that the system was not yet useful due to lack of baseline data in the database. Auditors also stated that the lack of uniformity across the TAC audit programs could be a source of delay for formatting data for input to AADITS.

\section{Canclusions}

One major area of improvement that the LRA and deputy assistant project manager both mentioned was the need to incorporate current and, if possible, historical audit data to the AADITS system. This system would allow trend analysis for various categories of findings. Such information might be of limited use for a very mature program but could be useful at the startup of similar DOE projects. 
The usefulness of the current radiological audit results is limited because most of the significant observations are a restatement of good practices the RAC already knows are in place.

The goals of the radiological audit program, as understood by the TAC auditors and management, are fulfilled adequately; however, it is questionable whether value is added to the UMTRA Project audit program through radiological audits at the current frequency and format.

\section{Recommendations}

The TAC audit procedure should be compared to the internal RAC audit process to eliminate duplicate areas of focus. A possible evolution for the radiological audit process would be to phase out the repetitive nuts-and-bolts audit items in favor of more programmatic-based reviews. Such reviews could focus on such issues as "How are new regulatory drivers and implementation guidance relayed and implemented through the health physics site managers?"

While auditors review previous audit reports to identify potential trends and problem areas, the formal AADITS software should be implemented as a repository for current and historical findings and observations. This action is necessary to perform trending analysis. Implementation of this system will require a processing of historical audit data for consistency of reporting, coding of observations and findings by subject or type, and entry into the system.

\subsection{HEALTH AND SAFETY AUDIT SUMMARY}

H\&S auditing is a systematic, documented, periodic, and objective review of facility operations and practices related to meeting accepted and required H\&S practices, as specified by Occupational Safety and Health Administration (OSHA) regulations, DOE orders, and the UMTRA Project Environmental, Health and Safety Plan (DOE, 1992). Audits are generally designed to accomplish the following (AIHA, 1994):

- Verify compliance with H\&S requirements.

- Evaluate the effectiveness of H\&S management systems in place.

- Assess risks from operations, materials, and work practices.

In H\&S auditing, three distinct types of auditing are recognized (Holman, 1994):

- Needs assessment audits - performed to establish the need for programs, procedures, and policies. Generally a free-form process using basic checklists.

- Comprehensive compliance audits - performed when programs are in place to establish the level of compliance. Generally includes use of checklists and inspections. 
- Management systems audits - performed to evaluate both the programs and the management systems in place to ensure compliance. Includes trending and root cause analysis.

Of importance for this ITR is what type of H\&S audit is expected versus what is performed by the TAC auditors. As observed during the Rifle audit, the current level of audit is essentially a comprehensive compliance audit against DOE orders and OSHA regulations. It is conducted to obtain detailed objective evidence with a focus on construction safety. No documentation was found indicating which type of audit is expected.

No comprehensive definition or scope of work was found that establishes TAC management protocols in the current H\&S audit program. There is a draft SOP titled Regulatory Compliance Department Audit Programs, but it is not specific. Section 2.0, "Scope," of this draft SOP states the following:

". . . audits assess the RAC effectiveness in protecting personnel, property and the environment as required by federal, and state laws and regulations, DOE Orders and Project-wide plans and procedures."

This ITR found no documented H\&S audit protocol. Section 4.1.4 of the draft SOP, "Audit Plan and Checklist" (Subsection a, "Health and Safety") provides some guidelines for auditors. Checklists are available for the auditors to use based on these guidelines. Not listed in these guidelines is the evaluation of management systems or programmatic issues.

The DOE UMTRA Project Office ES\&H Quality Assurance Guidelines (DOE, 1994) have been developed by DOE management for TAC auditors. These guidelines provide a basic framework for conducting TAC ES\&H audits. They do not provide protocols for conducting audits.

During interviews, the TAC audit team reported that H\&S audit teams are currently performing inspections rather than audits. The audit team focuses on objective evidence primarily obtained by physically surveying the site. The ITR confirmed this during the visit to the Rifle site.

Section 6.0 of the draft DOE UMTRA Project Office ES\&H Quality Assurance Guidelines provides for the audit report to include any findings and to list all objective evidence used to support the findings. Noteworthy practices and observations made by the TAC audit team are to be provided in the transmittal letter or as a separate attachment to the audit report.

\section{Conclusions}

There is insufficient emphasis by the TAC auditors on program or management issues beyond the site findings. The current audit program appears to more closely resemble an inspection rather than an audit. The audit team spends a significantly greater amount of 
time in the field evaluating compliance with physical control of hazards than in evaluating the implementation of management systems to ensure compliance.

A management systems audit would be preferable for the UMTRA Project, and the implementation of the audits is not as effective or efficient as it could be. Having the TAC auditors perform comprehensive compliance audits is redundant because a significant level of internal auditing is already performed by the RAC along with operational readiness reviews (ORR) and operational readiness evaluations (ORE) conducted by the DOE. There is a clearly defined industrial hygiene, safety, and health program in place.

The opening meetings and daily debriefings were not well organized and did not present a systematic approach to the audit process.

The lack of an established audit protocol prevents the auditors from following a systematic approach to auditing the UMTRA Project sites.

The current time committed to the audits is insufficient to perform a comprehensive compliance audit. Either more time is needed or a better focus is required. This would have the auditors concentrate on only a few key areas where the risk assessment indicates greater effort is needed to ensure the public's health and safety and that of the workers on the sites.

Trending and root cause analysis are not being performed as part of the TAC H\&S audits.

\section{Recommendations}

TAC management needs to commit to an H\&S management systems audit that focuses on the implementation of programs and management systems in place to ensure compliance. This includes trending and root cause analysis as major components of the audits.

TAC management should commit to developing specific audit protocols to be followed by the TAC auditors.

An adequate time for conducting audits needs to be provided. The time commitment needs to allow the auditors enough time to evaluate physical control compliance in the field and to review important program documents and records.

Auditors need to review information contained in internal audits conducted by the RAC . and the DOE ORRs/OREs as part of their review process.

TAC auditors need to be allowed to address programmatic issues identified from site objective evidence.

\subsection{ENVIRONMENTAL AUDIT SUMMARY}

The TAC audits are generally guided by site-specific procedures and program-specific audit checklists, and they proceed according to a predetermined schedule. Even so, the audit process is poorly defined, because the objectives of the audit program are not well 
specified. The measure of an effective audit process is the information the program provides. This information should be sufficient, that is, "factual, reliable and convincing, so that a prudent, informed person would be likely to reach the same conclusions as the auditor" (Holman, 1994). It should also be reliable, relevant, and useful as determined by the goals of the affected organizations. Thus, an effective audit program is "A process which collects, analyzes, interprets and documents information sufficient to achieve audit objectives" (Holman, 1994). It is the audit objectives that define the audit process.

Managers directing the TAC audit program reported that the sufficiency of audit data gathering was left to the professional judgment of individual auditors. Based on observations of the audit process, however, sufficiency is generally determined in the field by the RAC or by DOE participants. In particular, the auditors had to provide a nearly incontrovertible regulatory basis in order for the RAC to accept an observation as a finding. Given the poorly specified objectives of the audit program, coupled with the relative inexperience of the environmental auditors, such an incontrovertible basis was difficult to demonstrate.

Improving the audit process should start with clear program objectives and with audit staffing consistent with these objectives. The program should then be designed to provide information that is sufficient, reliable, relevant, and useful to each affected organization: the DOE, the TAC, and the RAC. This goal will be accomplished only through a cooperative effort-one that accommodates RAC managers and site personnel, as well as their perceptions of relevance and usefulness.

\subsection{QUALITY ASSURANCE AUDIT SUMMARY}

During the audit, neither the audited party nor the auditors reviewed written procedures. The quality or usefulness of the procedures was not evaluated. During the assessment process, the auditors did not record technical problems with any of the tests they observed. The evaluation was more a proficiency test for the staff rather than an evaluation of the procedures.

During preparation for this audit, several procedures evaluated for background dated from April 1988. The background reading book (for the ITR team to study prior to the review) contained procedures listed in the procedures status list as superseded.

\section{Recommendations}

Areas that are consistently evaluated with no deficiencies identified should be scheduled less frequently. A program-level evaluation needs to be conducted to determine what QA program elements have not been audited or where problems are suspected. All such areas should be audited. Resources need to be spent on program maintenance (refer to the items identified in Section 5.0). Maintenance includes establishing currency of documents and effective document control and distribution. Documents provided to assessment team members as part of their preparation for this ITR were out of date or possibly superseded. Such document control problems can degrade audit performance or work activities associated with the use of procedures. The impact of document control on the quality of work activities should be evaluated. 


\subsection{AUDIT REPORTING AND CORRECTIVE ACTIONS}

CRITERIA Have procedures been prepared to encourage prompt reporting of audit findings and preparation of corrective action plans and schedules? Do managers and staff involved in audit program implementation adhere to these procedures?

APPROACH Review the audit procedures to determine the mechanisms established for reporting audit findings and preparing corrective action plans and schedules.

Interview DOE, TAC, and RAC personnel to determine how these procedures are carried out.

Review past audit reports and corrective action schedules to verify that audit findings have been closed promptly. If corrective actions have not been completed by their scheduled closure dates, confirm that schedule changes were reviewed and approved in accordance with the applicable procedures.

\subsection{RADIOLOGICAL AUDIT SUMMARY}

Before performing a radiological field audit, TAC auditors review the most recent TAC audit reports to identify previous findings and/or observations that should be reviewed during the current audit. The LRA makes a separate checklist addressing previous findings and observations and, while on the site, visually inspects for proper implementation. Prior to the Rifle audit, no findings or significant observations in the previous audit report were identified as requiring current investigation. The most recent audit at Mexican Hat/Monument Valley in March 1994 required that findings and observations from the previous audit be reviewed.

The TAC auditors stated that the RAC has historically been responsive in implementing corrective actions.

\section{Conclusions}

The shortcomings of the audit review and reporting cycle have been discussed in several of the previous sections. The actual transmittal and resolution of observations and findings proceeds rather slowly.

\section{Recommendations}

Steps should be taken to streamline the reporting and corrective measures phase of the audit.

\subsection{HEALTH AND SAFETY AUDIT SUMMARY}

The ITR reviewed the most recent TAC audit reports for the Rifle site. The audit reports contained objective observations from the physical site inspections grouped into categories that support findings. 
The current reports reviewed during this ITR contained findings but did not identify management system deficiencies. Corrective actions are developed by RAC management based on the audit findings. The ITR team noted that corrective actions submitted often use training as a primary corrective action. This was the case when it appeared that management system deficiencies were the root cause for many findings.

\section{Section 6.1 of the DOE UMTRA Project Office ES\&H Quality Assurance Guidelines} (DOE, 1994) contains guidelines for TAC audit reports. The reports reviewed do not contain recommendations or a corrective action plan. These are left up to RAC management to establish based on the audit findings.

RAC site management indicated that it takes more than 1 month to receive the audit reports.

The TAC has developed a system for tracking corrective action items, including those developed by the RAC in response to TAC audit findings.

\section{Conclusions}

The RAC is generally notified of issues, and takes action to address the issues, fairly promptly. However, the current audit reporting process and the development of corrective actions are inefficient and slow. RAC site management reported that they are interested in promptly addressing issues presented in the audit reports.

Corrective action reports do not address root cause problems. They tend to focus on training and physical correction of identified findings without addressing management deficiencies. To be effective tools, H\&S audits need to go beyond the current method of reporting objective evidence and findings, and address management system and programmatic issues.

\section{Recommendations}

TAC management should direct TAC auditors to develop complete reports that address objective evidence, findings, recommendations, identification of management system deficiencies, and corrective actions.

The cover letter should not be used to report recommendations, observations, and other objective evidence that DOE or RAC management do not feel belong in the audit report. This practice affects the objectivity of the auditors and does not require an official response from RAC management.

The current time frame taken to complete audit reports should be reduced so that reports are in the hands of RAC site management within 1 month after the audit is completed.

The auditors must determine the validity of the findings based on objective evidence. 


\subsection{ENVIRONMENTAL AUDIT SUMMARY}

The TAC audit programs have incorporated detailed procedures for reporting the results of audits, as well as for identifying, approving, tracking, and closing corrective actions generated in response to audit findings. In general, the corrective action procedures appear to be working effectively. However, the audit reporting procedures currently emphasize the preparation of recommendations rather than the reporting of objective findings, thereby placing the responsibility for identifying appropriate corrective actions on the auditors.

The development of corrective actions to address audit findings should be the responsibility of those most familiar with the audited operations-in this case, the RAC. First, more than one approach may fulfill an environmental requirement. The approach selected for a given situation may depend on the availability of resources or on the preferences of the responsible manager. Second, where findings and recommendations are not clearly distinguished in an audit report, an outside agency may treat the recommendation as a finding that is both binding and enforceable. In this circumstance, an auditor's recommendation may create an unnecessary liability for the audited facility. Finally, identifying recommended actions during an audit reduces the amount of time available to the auditors to review site operations and prepare findings. The responsibility of the auditors should be limited to 1) preparing objective findings that clearly identify the nature of observed noncompliance and the regulatory basis for each finding, and 2) reviewing corrective action plans developed by the audited facility to ensure that the proposed actions address the observed noncompliance.

\subsection{QUALITY ASSURANCE AUDIT SUMMARY}

\section{Section 10.7.1 of the UMTRA Project Office Quality Assurance Program Plan (DOE,} 1993b) states "The audit report shall contain all findings and observations, regardless of magnitude or whether or not they were corrected immediately." Contrary to the above, as determined through interviews with various staff members, such items are often contained in the cover letter. The computer database for tracking corrective actions does not appear fully implemented. It is uncertain whether this provides sufficient assurance that followup and especially verification of closeout are efficient and effective.

Section 10.12.4 of the TAC Quality Assurance Program Plan (DOE, 1993c) states "The audit teams shall inspect all of the findings and observations from the previous audit." Contrary to this statement, not all of the findings and observations from the previous audit were inspected. This statement requires that both positive and negative findings and observations be inspected, even those included in cover letters.

Many items identified as part of the assessment of the audit process are not part of the audit process as such but are related to the QA program in general. The DOE and TAC program documents are not always consistent; as a result, the requirements for a particular activity are not clear. In some cases, the TAC appears to impose requirements on DOE activities. The documents should be evaluated to determine whether they describe work activities as they are intended to be carried out, especially since many of the documents carry issue dates that are not current. The audits as currently carried out 
provide a valuable function for the project as ongoing evaluations of geotechnical functions. These evaluations are needed for both technical and compliance purposes. These activities appear to provide a much-needed mechanism for technical communication and decision making.

Root causes should be determined when the severity of problems warrants it. It appears that trending based on performance indicators would aid the project. 


\subsection{RESPONSES TO QUESTIONS}

\section{A. Are the TAC organizational responsibilities for audits clearly defined?}

Radiological - Audit responsibilities for TAC auditors are defined in the radiological audit procedure. The procedure refers to a variety of technical audit areas covered in detail in audit checklists.

TAC management responsibilities with respect to the RAC and DOE are not written. The TAC managers stated that they were sometimes not certain of DOE responsibilities with respect to the audit and that higher-tier program plans contained vague or oblique definitions.

Health and safety - TAC organizational responsibilities for the audits are defined in a draft SOP. This draft establishes responsibilities for the Regulatory Compliance Department manager, lead auditor, and audit team members. This draft SOP provides a basic procedure for the audit process.

The documents that establish the TAC organizational responsibilities for audits are the TAC Management Plan (DOE, 1993a) and the UMTRA Project Audit/Surveillance Program Plan (DOE, 1988b). The TAC Management Plan establishes general organizational responsibilities for H\&S audits in Section 3.7.3, "Audit Activities." This section states that "health and safety staff of the TAC regulatory compliance department routinely conduct health and safety audits of RAC construction activities ..." Neither the TAC Management Plan nor the UMTRA Project Audit/Surveillance Program Plan is specific with regard to organizational responsibilities for the H\&S audit process.

While TAC policies, plans, and procedures define the responsibilities of TAC audit personnel reasonably well, those responsibilities are not always executed as defined because the TAC's audit responsibilities have not been integrated with those of the DOE and the RAC.

Environmental - While TAC policies, plans, and procedures define the responsibilities of TAC audit personnel reasonably well, those responsibilities are not always executed as defined because the TAC's audit responsibilities have not been integrated with those of the DOE and the RAC.

Quality assurance - TAC responsibilities are reasonably well defined; the problem is carrying out this responsibility. The TAC QA planning documents attempt to better define the requirements for the audit activities passed on to the TAC. The document hierarchy becomes less clear as it interfaces from organization to organization. The QA audit function does not identify program-level deficiencies.

\section{Is consistency of approach demonstrated throughout the project?}

Radiological - The radiological audit program has evolved over the past 10 years, and the TAC auditors and management agree that the radiological audits are consistent in implementation, documentation, and corrective actions. This interpretation is based on the fact that no major findings or recommendations (those affecting the integrity or efficiency of radiological measurements, excavation control, etc.) have resulted from audits in the past 2 to 3 years. 
Auditors consistently review previous audit reports and supplemental technical information to prepare future audit plan subject areas. The LRA stated that he had received formal AADITS training, but that the system was not yet useful because baseline data in the database was insufficient. It was also stated that the lack of uniformity across TAC audit programs could delay data formatting for input to AADITS.

While auditors review previous audit reports to identify potential trends and problem areas, the formalized AADITS software should be implemented as a repository for current and historical findings and observations. This action is necessary to perform trending analysis. Implementation of this system will require a processing of historical audit data for consistency of reporting, coding of observations and findings by subject or type, and entry into the system.

Health and safety - There appears to be a lack of consistency in the audit approaches for H\&S when compared to the other audit approaches used. For example, the radiological site audits have a defined scope of work, audit objectives, and audit protocols. H\&S audits, on the other hand, lack this consistent approach. In addition, recent changes in the way H\&S audits are conducted have changed how the reports are handled. In general, the H\&S audits are not as well-defined or as consistent as the other audits conducted for the UMTRA Project.

Environmental - From interviews conducted during this review, it appears that the UMTRA Project is not considered by Project participants to be governed by environmental requirements to the same extent as other DOE programs. The prevailing opinion is that environmental considerations are secondary to radiological, H\&S, and QA issues.

Quality assurance - The evaluations at field locations are consistent. These activities are called surveillances and are, in fact, surveillances, not audits. It could not be demonstrated that all program elements within the scope of QA are evaluated. Evidence of evaluation of TAC activities is minimal.

\section{B. What value are the TAC audit programs adding to the UMTRA Project?}

Radiological - The usefulness of the current radiological audit results is limited because most of the significant observations are a restatement of good practices the RAC already knows are in place.

The goals of the radiological audit program, as understood by the TAC auditors and management, are fulfilled adequately; however, it is questionable whether value is added to the UMTRA Project audit program through radiological audits at the current frequency and format.

Health and safety - From interviews conducted with members of the TAC, RAC, and DOE, the value of the TAC audits lies in improving the overall safety of the UMTRA Project sites. The TAC H\&S audits, however, do not address management system problems, programmatic issues, and best management practice issues. Considering the number of audits that are conducted at the UMTRA Project sites, internal RAC audits, and DOE ORRs/OREs, the value of the existing TAC H\&S audits is diluted because they do not address program-wide management issues or root causes. 
Environmental - Because of a limited number of findings generated by the audits, the existing environmental audit program would seem to imply substantial compliance with the regulations and may therefore contribute to a sense of security among TAC managers. However, the number of findings reflects the limitations of the existing audit program, not the compliance status of the sites. Deficiencies have not been noted by the audit teams because 1) little attention has been directed to compliance with administrative and procedural requirements; 2) the audit program does not highlight requirements that are considered by the regulatory agencies to be fundamental to compliance; 3) the auditors have not received guidance on assessing facility training programs; 4) the audit does not sufficiently consider the enforceable provisions of facility environmental plans and procedures; and 5) the auditors are not well informed of regulatory developments of consequence to UMTRA Project operations.

Quality assurance - Many items identified as part of the assessment of the audit process are not part of the audit process as such but are related to the QA program in general. The DOE and TAC program documents are not always consistent; as a result, the requirements for a particular activity are not clear. In some cases, the TAC appears to impose requirements on DOE activities. The documents should be evaluated to determine whether they describe work activities as they are intended to be carried out, especially since many of the documents are not current. The audits as currently carried out provide a valuable function for the UMTRA Project as ongoing evaluations of geotechnical functions. These evaluations are needed for both technical and compliance purposes. These activities appear to provide a much-needed mechanism for technical communication and decision making.

\section{Have trending and root cause analysis been performed?}

Radiological - Since the AADITS system is not in full use, numerical analysis for trending and root cause analyses are not used. Historical audit data are reviewed informally to identify trends to be investigated in the current audit.

Health and safety - Currently, trending and root cause analysis are not being performed as part of the H\&S audit processes.

Environmental - Currently, trending and root cause analysis are not being performed as part of the environmental audit processes.

Quality assurance - Root causes should be determined when the severity of problems warrants it. It appears that trending based on performance indicators would aid the project. TAC staff members understood root cause. The problems with its use were associated with knowing when root cause analysis was needed and whose responsibility it was to do the analysis.

\section{What changes should be made to the programs to increase their value?}

Radiological - The issues concerned with assignment of responsibility can be addressed by preparing a clearer, more consistent policy statement in all applicable UMTRA Project program documents. 
The participation of a technically experienced individual new to the UMTRA Project audit program was beneficial to the audit process and should be adopted as a requirement in the radiological audit procedure.

If current audit program objectives are retained, they should be formally stated in UMTRA Project program documents, including the TAC Management Plan and QAPP. However, it is recommended that TAC management assess whether more value would be added to the radiological audit program by modifying objectives to focus more on information transfer and dissemination, rather than a purely technical nuts-and-bolts audit of a mature radiological protection program.

The TAC audit procedure should be compared to the internal RAC audit process to eliminate duplicate areas of focus. A possible evolution for the radiological audit process would be to phase out the repetitive nuts-and-bolts level audit items in favor of a more programmatic-based review. This type of review could focus on issues such as "How are new regulatory drivers and implementation guidance relayed and implemented through the health physics site managers?"

While auditors review previous audit reports to identify potential trends and problem areas, the formal AADITS software should be implemented as a repository for current and historical findings and observations. This is necessary to perform trending analysis. Implementing this system will require that historical audit data be processed for consistency of reporting, coding of observations and findings by subject or type, and entry into the system.

Health and safety - Changes that need to be made to the existing TAC H\&S audit program include the following:

- Establish clear H\&S audit objectives that are measurable and achievable.

- Establish an audit protocol and a scope of work for the auditors to follow. This can include the refinement of the existing audit checklist currently being used.

- Give auditors adequate time to conduct the audits. The time available for H\&S audits does not appear adequate to conduct a comprehensive, detailed audit. The auditors currently focus a substantial amount of time on field observations and less time on records, program review, and management systems evaluations.

- Authorize and direct auditors to address programmatic issues and management systems deficiencies.

- Encourage auditors to use their knowledge and experience to suggest appropriate corrective actions based on audit findings. The suggestions should not be considered binding.

- Direct auditors to perform root cause and trending analysis, as appropriate, as part of the audit process. Results of root cause investigations and trending analysis need to become a part of the audit documentation.

- Direct TAC auditors to determine the validity of their findings. 
- Direct auditors to evaluate internal audits conducted by the RAC and the DOE as part of the TAC audit process.

- Reduce the time to complete audit reports so that the reports are in the hands of RAC site management within 1 month after the audit is completed. RAC site management reported that the audit process takes too long for results to be received.

- Review the use of the cover letter for reporting noteworthy practices, recommendations, or observations. The cover letter does not require an official response and, in many cases, the items placed in these cover letters are significant enough to warrant an appropriate response from $\mathrm{RAC}$ management.

Environmental - The audit process should have clear program objectives, and audit staffing should be consistent with these objectives. The program should provide information that is sufficient, reliable, relevant, and useful to each organization. This will be accomplished only through a cooperative effort that accommodates RAC managers and site personnel and takes into account their perceptions of relevance and usefulness.

In the end, an audit should foster change. Any force that brings change can also expect resistance. Audit program development should therefore consider methods for overcoming resistance to change. Those most likely to resist should be involved in developing the audit program; their involvement should ultimately contribute to the program's effectiveness.

Quality assurance - The QA program needs to be evaluated to determine whether it provides the necessary controls and implementation. Full program evaluation is not possible until implementation is in place. At that time, effective performance indicators can be identified and tracked in time. DQOs are much like performance indicators and are usable for trending. These are of value on all environmental projects. Root cause is understood but not well implemented. Root cause should be used for systemic problems.

\section{How is the information from audits used and by whom?}

Radiological - RAC management uses audit findings to correct site-specific problems. Both the RAC and TAC use audit findings to identify areas of radiological audit program improvement.

Health and safety - RAC site management uses information from the audits to correct physical deficiencies found in a specific operation. TAC management uses information from the audits to track the completion of corrective actions to address the hazards found during prior audits and to serve as a guideline for targeting future audits.

Environmental - The auditors use information from past audits to identify persistent or repeated noncompliance with applicable regulations, policies, and procedures. Otherwise, the audits may be furnishing little useful information to the DOE, TAC, or RAC.

Quality assurance - The audit information does not appear to be as useful to either TAC staff or site staff as it should be. This is supported by the findings in Sections 3.0 and 7.0. The commitment to quality activities is present. Full implementation appears to be an area where 
additional evaluation is needed. The audit team used the audit process to solve problems in a rather, unconventional but necessary, way.

\section{E. What areas are not being audited that should be?}

Radiological - When asked if they believed the audit program objectives were achieved, the auditors and the deputy assistant project manager stated that program objectives had been achieved. Furthermore, they felt the objectives could continue to be achieved with less frequent audits and perhaps through participation in beginning-of-year readiness reviews. RAC site health physics managers were less inclined to believe these objectives were met through the TAC audit program. RAC managers believed that internal RAC audits were more effective at identifying potential technical problems and noncompliance issues. The RAC health physics manager stated that internal audit results were not forwarded to the TAC for review. Both the Rifle and Mexican Hat site health physics managers stated that the TAC audits added to the level of readiness of site personnel.

If current audit program objectives are retained, they should be formally stated in UMTRA Project programmatic documents, including the TAC Management Plan and QAPP. However, it is recommended that DOE, TAC, and RAC management assess whether more value would be added to the radiological audit program by modifying objectives to focus more on programmatic issues, information transfer, and information dissemination.

Health and safety - Currently, programmatic issues and management systems are not fully audited by the TAC H\&S audit team. Specific programs and procedures are reviewed to evaluate on-site implementation and compliance. Still, the audits more closely resemble a site inspection than an audit, which would focus equally on inspection, programs, procedures, and management systems.

Environmental - The environmental audit program should either be restructured around clear objectives (with audit staffing consistent with these objectives) and procedures designed to provide sufficient, reliable, relevant, and useful information, or it should be discontinued. In particular, this program should include the following:

- A thorough review of environmental plans, procedures, and records to verify that they satisfy regulatory requirements.

- Consideration of requirements that have been identified by the regulatory agencies as fundamental to compliance, such as the methods used to identify and characterize hazardous waste.

- Procedures for assessing facility training programs to determine that performance-based standards have been met.

- Consideration of enforceable requirements that have been identified in environmental plans prepared by each facility, such as the inspection and training schedules outlined in facility SPCC plans. 
Quality assurance - Refer to the items in Section 5.4. Areas that are consistently evaluated with no deficiencies identified should be scheduled less frequently. A program-level evaluation needs to be conducted to determine what QA program elements have not been audited or are suspected to contain problems. All such areas should be audited. Resources need to be applied to program maintenance.

\section{What areas are being audited that shouldn't be?}

Radiological - The TAC audit procedure should be compared to the internal RAC audit process to eliminate duplicate areas of focus. A possible evolution for the radiological audit process would be to phase out the repetitive nuts-and-bolts level audit items in favor of more programmatic-based review.

Health and safety - While all areas should be audited as part of the H\&S process, less time could be spent on the industrial hygiene monitoring program reviews. The greatest hazards presented on these sites are created by construction activities; these would include falls, being struck by objects, excavations, and maintenance shop safety, among others.

Environmental - The environmental audits should consider environmental risks only to the extent that the DOE, the TAC, and the RAC agree on the acceptable basis for findings.

Quality assurance - Emphasis is placed on areas where no negative findings have been identified. Fewer audits would be appropriate in these areas.

\section{F. How are staff chosen for audit teams?}

Radiological - Auditor credentials are reviewed by the Regulatory Compliance Department manager, and it is necessary that a lead auditor have participated in at least six audits (two nonUMTRA audits). No formal system of documenting changes to current standards and requirements exists. Auditors are charged to stay current in these areas, and the Regulatory Compliance Department manager transmits information as received in the form of memos.

Health and safety - Currently, there is an established H\&S audit team. Job descriptions are provided for both an H\&S specialist and a construction safety specialist. The job descriptions define required skills, knowledge, experience, and duties and responsibilities. Audit team members are selected based on meeting these basic job descriptions.

Environmental - The TAC has attempted to retain qualified individuals to staff the TAC audit programs and to keep those individuals abreast of applicable requirements and standards. The individuals currently involved in environmental audits each possess more than 5 years of experience in environmental compliance activities.

Quality assurance - The independence of the audit/evaluation function is critical to the effectiveness of an audit. This independence protects the evaluation from allegations of conflict of interest and allows the auditors to be free from conflicts. Long-term relationships at either the individual or organizational level decrease actual or perceived independence. When evaluating mature programs, auditors should maintain their objectivity and guard against allowing activities to slip into a state of complacency. 
The interorganizational decision-making process deserves more recognition and should be further strengthened.

\section{Are the audit staff qualification requirements adequate?}

Radiological - The LRA had significant experience on the UMTRA Project audit program and in auditing private-sector facilities. His technical background was more than adequate to assess the technical objectives and procedures of the RAC and to assess changing regulatory conditions potentially affecting the Project. The trainee had no UMTRA Project audit experience, but he had significant private-industry experience that was demonstrated through the audit process. These staff members possess adequate qualifications to perform the audit functions.

Health and safety - Based on a review of the resumes of the two current H\&S auditors, the current staff possesses adequate qualifications to perform audits.

Environmental - The capabilities of an auditor come largely from experience gained by conducting audits. This is experience that the individuals assigned to perform environmental audits do not possess in large measure.

The TAC should make sure that individuals selected as auditors possess the necessary mix of regulatory knowledge, understanding of audit techniques and approaches, and familiarity with construction site operations, consistent with audit program objectives.

Quality assurance - Audit staff qualifications need to be based on background, technical experience, and independence. Additional training in auditing skills is needed for full-scope program audits. Surveillances are generally easier to perform and the activities are easier to control. Additional training may be required if full-scope audits are to be performed.

Audit staff should receive formal external audit training and have the chance to participate in or observe audits outside the Project.

\section{How do team members stay current in their field?}

Radiological - The LRA has attended formal auditor training and published a variety of papers on QA as related to auditing. Technical exchanges with other auditors attending these conferences are used to share ideas and practices; this allows the LRA to remain current in the technical audit subject areas.

Health and safety - Both members of the H\&S audit team stay current in the field through professional development, training, review of pertinent Project SOPs and DOE orders, and professional work experience. A database program set up by the TAC provides a tracking system for monitoring project-related training, education, and professional development.

Environmental - Both environmental audit team members indicated ready access to such needed tools as the Federal Register and the Bureau of National Affairs Environment Reporter. The TAC audit programs have also created mechanisms for overcoming auditor inexperience through a mentorship program. This program should continue and be strengthened. 
Quality assurance - QA staff need ongoing training, particularly now as environmental QA programs change. Technical growth is also important. ITR team members did not have an opportunity to determine whether QA staff possess broad QA or technical knowledge, because the activity observed during the review was narrow in scope. 


\subsection{REFERENCES}

AIHA (American Industrial Hygiene Association), 1994. Industrial Hygiene Auditing: A Manual for Practice, American Industrial Hygiene Association, Fairfax, Virginia.

DOE (U.S. Department of Energy), 1994. DOE UMTRA Project Office ES\&H Quality Assurance Guidelines, draft, February 1994, available at the U.S. Department of Energy, UMTRA Project Office, Albuquerque Operations Office, Albuquerque, New Mexico.

DOE (U.S. Department of Energy), 1993a. TAC Management Plan, DOE/AL/62350-38F, September 1993, prepared by the U.S. Department of Energy, UMTRA Project Office, Albuquerque Operations Office, Albuquerque, New Mexico.

DOE (U.S. Department of Energy), 1993b. UMTRA Project Office Quality Assurance Program Plan, DOE/AL/62350-76, Rev. 5, November 1993, prepared by the U.S. Department of Energy, UMTRA Project Office, Albuquerque Operations Office, Albuquerque, New Mexico.

DOE (U.S. Department of Energy), 1993c. UMTRA Technical Assistance Contractor Quality Assurance Program Plan, DOE/AL/62350-56, Rev. 4, October 1993, prepared by the U.S. Department of Energy, UMTRA Project Office, Albuquerque Operations Office, Albuquerque, New Mexico.

DOE (U.S. Department of Energy), 1992. UMTRA Project Environmental Health and Safery Plan, UMTRA-DOE/AL-150224.0006, May 1992, prepared by the U.S. Department of Energy, UMTRA Project Office, Albuquerque Operations Office, Albuquerque, New Mexico.

DOE (U.S. Department of Energy), 1988a. Guidelines for Conducting Radiological Surveillances of Remedial Action Activities at UMTRA Processing Sites, unnumbered, May 1988, prepared by the U.S. Department of Energy, UMTRA Project Office, Albuquerque Operations Office, Albuquerque, New Mexico.

DOE (U.S. Department of Energy), 1988b. UMTRA Project Audit/Surveillance Program Plan, UMTRA-DOE/AL-400326.0000, April 1988, prepared by the U.S. Department of Energy, UMTRA Project Office, Albuquerque Operations Office, Albuquerque, New Mexico.

JEG (Jacobs Engineering Group Inc.), n.d. Albuquerque Operations Manual, standard operating procedures, prepared by Jacobs Engineering Group Inc. for the U.S. Department of Energy, UMTRA Project Office, Albuquerque Operations Office, Albuquerque, New Mexico.

Holman, S. H., 1994. "Environmental Safety and Health Auditing for Continuous Improvement," paper presented at the American Industrial Hygiene Conference and Exhibition, May 1994, Anaheim, California. 


\section{CODE OF FEDERAL REGULATIONS}

40 CFR Part 112, Oil Pollution Prevention, U.S. Environmental Protection Agency (1994).

\section{DOE ORDERS}

DOE Order 5700.6C, Quality Assurance, August 21, 1991, Office of Nuclear Energy and Office of Environment, Safety, and Health, U.S. Department of Energy, Washington, D.C.

\section{FEDERAL REGISTER}

51 FR 25004, "Environmental Auditing Policy Statement," U.S. Environmental Protection Agency, July 9, 1986. 
APPENDIX A

SCOPE OF WORK FOR INDEPENDENT TECHNICAL REVIEW

OF

TAC AUDIT PROCEDURES 


\section{JACOBS ENGINEERING GROUP INC.}

2155 LOUISIANA NE, SUITE 10,000 • ALBUQUERQUE, NEW MEXICO 87110

TELEPHONE (505) 845-4646

February 21, 1994

Albert R. Chernoff

UMTRA Project Manager

U.S. Department Of Energy

Uranium Mill Tailings Remedial Action

Project Office

5301 Central Avenue, N.E., Suite 1720

Albuquerque, New Mexico 87108

Attention: Frank Bosiljevac/Milt Scoutaris

Re: Scope Of Work For Independent Technical Review Of TAC Audit Procedures

Contract No. DE-AC04-91AL62350

Dear Mr. Chernoff:

Enclosed please find a draft scope of work for an Independent Technical Review (ITR) of the TAC's Audit Program. This review is being proposed to resolve specific issues that have been raised by TAC and DOE staff, and to ensure that the TAC's audit programs are being conducted in an efficient and effective manner.

This is considered to be a Level I ITR as defined in the revised ITR Implementation Plan dated January 8, 1993, and will therefore require your approval (form enclosed.) We propose to complete this ITR by April 15, 1994. To the extent practicable, results from this ITR are to be available to factor in to audits that will be performed during the upcoming construction season.

If you approve of this proposed ITR, please sign and return the attached form. If you have any questions or comments, please call Mike Kearney (884-5050) or me.

Very truly yours, JACOBS ENGINEERING GROUP INC.

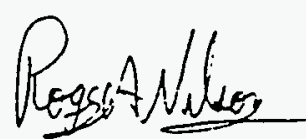

Roger A. Nelson

Project Manager, UMTRA

RAN:js

Enclosure 


\section{TAC Audit Program Independent Technical Review}

Scope of Work: This Level I Independent Technical Review (ITR) is to examine the practices and procedures of all TAC audit programs. The purpose of this review is to ensure that the TAC audit programs are effective and are conducted in an efficient manner. The reviewers will examine the appropriate SOP's and qualifications of the TAC audit personnel, and observe field activities. Areas where improvements can be made will be noted in the groups outbriefing and letter report. Specific questions which the group will address are:

a. Are the TAC organizational responsibilities for audits clearly defined? is consistency of approach demonstrated throughout the Project?

b. What value are the TAC audit programs adding to the UMTRA Project? Has trending and root cause analysis been performed?

c. What changes should be made to the programs to increase their value?

d. How is the information from audits used and by whom?

e. What areas are not being audited that should be? What areas are being audited that shouldn't be?

f. How are staff chosen for audit teams? Are the audit staff qualification requirements adequate? How do team members stay current with their field?

Components of the Review: The ITR Team will consist of the ITR Coordinator and four experts in the fields of quality assurance auditing, health and safety auditing, rad auditing, geotechnical testing, and environmental auditing. The reviewers will be provided a package of material that gives a brief background of the UMTRA Project and each of the audit programs, all applicable SOP's, audit plans, and example audit reports. Reviewer's will be expected to thoroughly review this material and identify individuals that they need to meet with and activities they need to observe prior to traveling to Albuquerque. The reviewers will spend one and one-half days in discussions and interviews with TAC, RAC, and DOE management and staff, will travel to one or more sites to observe audit practices in the field (two days total), then reconvene in Albuquerque for an informal outbriefing with TAC and DOE managers and to formulate the final report.

Independent Technical Reviewer Qualifications: The reviewer's experience must include significant audit program administration and direct field auditing in the area they will review. Reviewers must be certified lead auditors. (One reviewer must have experience in the auditing of geotechnical testing.)

ITR Team Coordinator:

Michael S. Kearney, Senior Program Manager

Roy F. Weston, Inc.

6501 Americias Parkway, NE

Suite 800

Albuquerque, New Mexico 87110

(505) 884-5050/fax 5388 
Deliverables: The Team will report their observations, conclusions, and recommendations informally at an outbriefing to be held in Albuquerque. This information will be formally documented in a letter report due to the ITR Team Coordinator no later than two calendar weeks after the outbriefing and issued by April 15, 1994.

Budget: The four technical experts are allotted 96 hours each. This time is to cover background reading ( 2 days), travel to Albuquerque ( 1 day each way), time in Albuquerque and at the sites ( 8 hours/day $\times 5$ days), and report writing ( 3 days). Travel costs will be reimbursable under the terms of the FAR. The Team Coordinator is allocated a budget of 80 hours for similar activities. (total $=464$ hours)

Schedule: Work on this ITR is proposed to begin upon DOE's approval, and to be completed by April 15, 1994. The week of March 13, 1994 is targeted for the discussions in Albuquerque and the visits to the site(s). To the extent practicable, the results of this ITR are to be available and be factored in to the field audits that are to be performed during the coming construction season. 
Independent Technical Review Approval TAC Audit Procedures
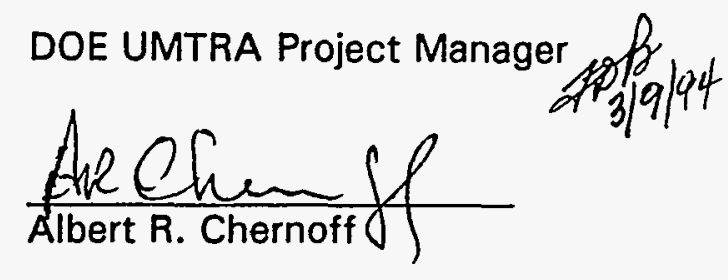

Date $3 / 11 / 94$
TAC UMTRA Project Manager

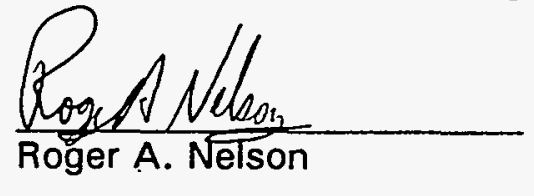

Date $2 / 21 / 94$ 


\section{APPENDIX B \\ ENVIRONMENTAL PROTECTION AGENCY \\ ENVIRONMENTAL AUDITING POLICY STATEMENT}

51 FR 25004

JULY 9, 1986 


\title{
ENVIRONMENTAL PROTECTION AGENCY
}

\author{
[OPPE-FRL-3046-6]
}

\section{Environmental Auditing Policy Statement}

AGENCY: Environmental Protection Agency (EPA)

ACTION: Final policy statement.

SUMMARY: It is EPA policy to encourage the use of environmental auditing by regulated entities to help achieve and maintain compliance with environmental laws and regulations, as well as to help identify and correct unregulated environmental hazards. EPA first published this policy as interim guidance on November 8, 1985 (50 FR 46504). Based on comments received regarding the interim guidance, the Agency is issuing today's final policy statement with only minor changes.

This final policy statement specifically:

- Encourages regulated entities to develop, implement and upgrade environmental auditing programs;

- Discusses when the Agency may or may not request audit reports;

- Explains how EPA's inspection and enforcement activities may respond to regulated entities' efforts to assure compliance through auditing;

- Endorses environmental auditing at federal facilities;

- Encourages state and local environmental auditing initiatives; and

- Outlines elements of effective audit programs.

Environmental auditing includes a variety of compliance assessment techniques which go beyond those legally required and are used to identify actual and potential environmental problems. Effective environmental auditing can lead to higher levels of overall compliance and reduced risk to human health and the environment. EPA endorses the practice of environmental auditing and supports its accelerated use by regulated entities to help meet the goals of federal, state and local environmental requirements. However, the existence of an auditing program does not create any defense to, or otherwise limit, the responsibility of any regulated entity to comply with applicable regulatory requirements.

States are encouraged to adopt these or similar and equally effective policies in order to advance the use of environmental auditing on a consistent, nationwide basis.

DATES: This final policy statement is effective July 9, 1986. 


\section{FOR FURTHER INFORMATION CONTACT:}

Leonard Fleckenstein, Office of Policy, Planning and Evaluation, (202) 382-2726; or Cheryl

Wasserman, Office of Enforcement and Compliance Monitoring, (202) 382-7550.

\section{SUPPLEMENTARY INFORMATION:}

\section{ENVIRONMENTAL AUDITING POLICY STATEMENT}

\section{Preamble}

On November 8, 1985 EPA published an Environmental Auditing Policy Statement, effective as interim guidance, and solicited written comments until January 7, 1986.

Thirteen commenters submitted written comments. Eight were from private industry. Two commenters represented industry trade associations. One federal agency, one consulting firm and one law firm also submitted comments.

Twelve commenters addressed EPA requests for audit reports. Three comments per subject were received regarding inspections, enforcement response and elements of effective environmental auditing. One commenter addressed audit provisions as remedies in enforcement actions, one addressed environmental auditing at federal facilities, and one addressed the relationship of the policy statement to state or local regulatory agencies. Comments generally supported both the concept of a policy statement and the interim guidance, but raised specific concerns with respect to particular language and policy issues in sections of the guidance.

\section{General Comments}

Three commenters found the interim guidance to be constructive, balanced and effective at encouraging more and better environmental auditing.

Another commenter, while considering the policy on the whole to be constructive, felt that new and identifiable auditing "incentives" should be offered by EPA. Based on earlier comments received from industry, EPA believes most companies would not support or participate in an "incentives-based" environmental auditing program with EPA. Moreover, general promises to forgo inspections or reduce enforcement responses in exchange for companies' adoption of environmental auditing programs - the "incentives" most frequently mentioned in this context are fraught with legal and policy obstacles.

Several commenters expressed concern that states or localities might use the interim guidance to require auditing. The Agency disagrees that the policy statement opens the way for states and localities to require auditing. No EPA policy can grant states or localities any more (or less) authority than they already possess. EPA believes that the interim guidance effectively encourages voluntary auditing. In fact, Section II.B. of the policy states: "because audit quality depends to a large degree on genuine management commitment to the program and its objectives, auditing should remain a voluntary program." 
Another commenter suggested that EPA should not expect an audit to identify all potential problem areas or conclude that a problem identified in an audit reflects normal operations and procedures. EPA agrees that an audit report should clearly reflect these realities and should be written to point out the audit's limitations. However, since EPA will not routinely request audit reports, the Agency does not believe these concerns raise issues which need to be addressed in the policy statement.

A second concern expressed by the same commenter was that EPA should acknowledge that environmental audits are only part of a successful environmental management program and thus should not be expected to cover every environmental issue or solve all problems. EPA agrees and accordingly has amended the statement of purpose which appears at the end of this preamble.

Yet another commenter thought EPA should focus on environmental performance results (compliance or noncompliance), not on the processes or vehicles used to achieve those results. In general, EPA agrees with this statement and will continue to focus on environmental results. However, EPA also believes that such results can be improved through Agency efforts to identify and encourage effective environmental management practices, and will continue to encourage such practices in non-regulatory ways.

A final general comment recommended that EPA should sponsor seminars for small businesses on how to start auditing programs. EPA agrees that such seminars would be useful. However, since audit seminars already are available from several private sector organizations, EPA does not believe it should intervene in that market, with the possible exception of seminars for government agencies, especially federal agencies, for which EPA has a broad mandate under Executive Order 12088 to provide technical assistance for environmental compliance.

\section{Requests for Reports}

EPA received 12 comments regarding Agency requests for environmental audit reports, far more than on any other topic in the policy statement. One commenter felt that EPA struck an appropriate balance between respecting the need for self-evaluation with some measure of privacy, and allowing the Agency enough flexibility of inquiry to accomplish future statutory missions. However, most commenters expressed concern that the interim guidance did not go far enough to assuage corporate fears that EPA will use audit reports for environmental compliance "witch hunts." Several commenters suggested additional specific assurances regarding the circumstances under which EPA will request such reports.

One commenter recommended that EPA request audit reports only "when the Agency can show. the information it needs to perform its statutory mission cannot be obtained from the monitoring, compliance or other data that is otherwise reportable and/or accessible to EPA, or where the Government deems an audit report material to a criminal investigation." EPA accepts this recommendation in part. The Agency believes it would not be in the best interest of human health and the environment to commit to making a "showing" of a compelling information need before ever requesting an audit report. While EPA may normally be willing to do so, the Agency cannot rule out in advance all circumstances in which such a showing may not be possible.

However, it would be helpful to further clarify that a request for an audit report or a portion of a report normally will be made when needed information is not available by alternative means. Therefore, EPA has revised Section III.A., paragraph two and added the phrase: "and usually 
made where the information needed cannot be obtained from monitoring, reporting or other data otherwise available to the Agency."

Another commenter suggested that (except in the case of criminal investigations) EPA should limit requests for audit documents to specific questions. By including the phrase "or relevant portions of a report" in Section III.A., EPA meant to emphasize it would not request an entire audit document when only a relevant portion would suffice. Likewise, EPA fully intends not to request even a portion of a report if needed information or data can be otherwise obtained. To further clarify this point EPA has added the phrase, "most likely focused on particular information needs rather than the entire report," to the second sentence of paragraph two, Section III.A. Incorporating the two comments above, the first two sentences in paragraph two of final Section III.A. now read: "EPA's authority to request an audit report, or relevant portions thereof, will be exercised on a case-by-case basis where the Agency determines it is needed to accomplish a statutory mission or the Government deems it to be material to a criminal investigation. EPA expects such requests to be limited, most likely focused on particular information needs rather than the entire report, and usually made where the information needed cannot be obtained from monitoring, reporting or other data otherwise available to the Agency."

Other commenters recommended that EPA not request audit reports under any circumstances, that requests be "restricted to only those legally required," that requests be limited to criminal investigations, or that requests be made only when EPA has reason to believe "that the audit programs or reports are being used to conceal evidence of environmental noncompliance or otherwise being used in had faith." EPA appreciates concerns underlying all of these comments and has considered each carefully. However, the Agency believes that these recommendations do not strike the appropriate balance between retaining the flexibility to accomplish EPA's statutory missions in future, unforeseen circumstances, and acknowledging regulated entities' need to self-evaluate environmental performance with some measure of privacy. Indeed, based on prime informal comments, the small number of formal comments received, and the even smaller number of adverse comments, EPA believes the final policy statement should remain largely unchanged from the interim version.

\section{Elements of Effective Environmental Auditing}

Three commenters expressed concerns regarding the seven general elements EPA outlined in the Appendix to the interim guidance.

One commenter noted that were EPA to further expand or more fully detail such elements, programs not specifically fulfilling each element would then be judged inadequate. EPA agrees that presenting highly specific and prescriptive auditing elements could be counter-productive by not taking into account numerous factors which vary extensively from one organization to another, but which may still result in effective auditing programs. Accordingly, EPA does not plan to expand or more fully detail these auditing elements.

Another commenter asserted that states and localities should be cautioned not to consider EPA's auditing elements as mandatory steps. The Agency is fully aware of this concern and in the interim guidance noted its strong opinion that "regulatory agencies should not attempt to prescribe the precise form and structure of regulated entities' environmental management or auditing programs." While EPA cannot require state or local regulators to adopt this or similar 
policies, the Agency does strongly encourage them to do so, both in the interim and final policies.

A final commenter thought the Appendix too specifically prescribed what should and what should not be included in an auditing program. Other commenters, on the other hand, viewed the elements described as very general in nature. EPA agrees with these other commenters. The elements are in no way binding. Moreover, EPA believes that most mature, effective environmental auditing programs do incorporate each of these general elements in some form, and considers them useful yardsticks for those considering adopting or upgrading audit programs. For these reasons EPA has not revised the Appendix in today's final policy statement.

\section{Other Comments}

Other significant comments addressed EPA inspection priorities for, and enforcement responses to, organizations with environmental auditing programs.

One commenter, stressing that audit programs are internal management tools, took exception to the phrase in the second paragraph of section IIl.B.1. of the interim guidance which states that environmental audits can 'complement' regulatory oversight. By using the word 'complement' in this context, EPA does not intend to imply that audit reports must be obtained by the Agency in order to supplement regulatory inspections. 'Complement' is used in a broad sense of being in addition to inspections and providing something (i.e., self-assessment) which otherwise would be lacking. To clarify this point EPA has added the phrase "by providing self-assessment to assure compliance" after "environmental audits may complement inspections" in this paragraph.

The same commenter also expressed concern that, as EPA sets inspection priorities, a company having an audit program could appear to be a 'poor performer' due to complete and accurate reporting when measured against a company which reports something less than required by law. EPA agrees that it is important to communicate this fact to Agency and state personnel, and will do so. However, the Agency does not believe a change in the policy statement is necessary.

A further comment suggested EPA should commit to take auditing programs into account when assessing all enforcement actions. However, in order to maintain enforcement flexibility under varied circumstances, the Agency cannot promise reduced enforcement responses to violations at all audited facilities when other factors may be overriding. Therefore the policy statement continues to state that EPA may exercise its decretion [sic] to consider auditing programs as evidence of honest and genuine efforts to assure compliance, which would then be taken into account in fashioning enforcement responses to violations.

A final commenter suggested the phrase "expeditiously correct environmental problems" not be used in the enforcement context since it implied EPA would use an entity's record of correcting nonregulated matters when evaluating regulatory violations. EPA did not intend for such an inference to be made. EPA intended the term "environmental problems" to refer to the underlying circumstances which eventually lead up to the violations. To clarify this point, EPA is revising the first two sentences of the paragraph to which this comment refers by changing "environmental problems" to "violations and underlying environmental problems" in the first sentence and to "underlying environmental problems" in the second sentence. 
In a separate development EPA is preparing an update of its January 1984 Federal Facilities Compliance Strategy, which is referenced in section III. C. of the auditing policy. The Strategy should be completed and available on request from EPA's Office of Federal Activities later this year.

EPA thanks all commenters for responding to the November 8, 1985 publication. Today's notice is being issued to inform regulated entities and the public of EPA's final policy toward environmental auditing. This policy was developed to help (a) encourage regulated entities to institutionalize effective audit practices as one means of improving compliance and sound environmental management, and (b) guide internal EPA actions directly related to regulated entities' environmental auditing programs.

EPA will evaluate implementation of this final policy to ensure it meets the above goals and continues to encourage better environmental management, while strengthening the Agency's own efforts to monitor and enforce compliance with environmental requirements.

\section{General EPA Policy on Environmental Auditing}

\section{A. Introduction}

Environmental auditing is a systematic, documented, periodic and objective review by regulated entities ${ }^{1}$ of facility operations and practices related to meeting environmental requirements. Audits can be designed to accomplish any or all of the following: verify compliance with environmental requirements; evaluate the effectiveness of environmental management systems already in place; or assess risks from regulated and unregulated materials and practices.

Auditing serves as a quality assurance check to help improve the effectiveness of basic environmental management by verifying that management practices are in place, functioning and adequate. Environmental audits evaluate, and are not a substitute for, direct compliance activities such as obtaining permits, installing controls, monitoring compliance, reporting violations, and keeping records. Environmental auditing may verify but does not include activities required by law, regulation or permit (e.g., continuous emissions monitoring, composite correction plans at wastewater treatment plants, etc.). Audits do not in any way replace regulatory agency inspections. However, environmental audits can improve compliance by complementing conventional federal, state and local oversight.

The appendix to this policy statement outlines some basic elements of environmental auditing (e.g., auditor independence and top management support) for use by those considering implementation of effective auditing programs to help achieve and maintain compliance.

\footnotetext{
1"Regulated entities" include private firms and public agencies with facilities subject to environmental regulation. Public agencies can include federal, state or local agencies as well as special-purpose organizations such as regional sewage commissions.
} 
Additional information on environmental auditing practices can be found in various published materials. ${ }^{2}$

Environmental auditing has developed for sound business reasons, particularly as a means of helping regulated entities manage pollution control affirmatively over time instead of reacting to crises. Auditing can result in improved facility environmental performance, help communicate effective solutions to common environmental problems, focus facility managers' attention on current and upcoming regulatory requirements, and generate protocols and checklists which help facilities better manage themselves. Auditing also can result in better-integrated management of environmental hazards, since auditors frequently identify environmental liabilities which go beyond regulatory compliance. Companies, public entities and federal facilities have employed a variety of environmental auditing practices in recent years. Several hundred major firms in diverse industries now have environmental auditing programs, although they often are known by other names such as assessment, survey, surveillance, review or appraisal.

While auditing has demonstrated its usefulness to those with audit programs, many others still do not audit. Clarification of EPA's position regarding auditing may help encourage regulated entities to establish audit programs or upgrade systems already in place.

\section{B. EPA Encourages the Use of Environmental Auditing}

EPA encourages regulated entities to adopt sound environmental management practices to improve environmental performance. In particular, EPA encourages regulated entities subject to environmental regulations to institute environmental auditing programs to help ensure the adequacy of internal systems to achieve, maintain and monitor compliance. Implementation of environmental auditing programs can result in better identification, resolution and avoidance of environmental problems, as well as improvements to management practices. Audits can be conducted effectively by independent internal or third party auditors. Larger organizations generally have greater resources to devote to an internal audit team, while smaller entities might be more likely to use outside auditors.

Regulated entities are responsible for taking all necessary steps to ensure compliance with environmental requirements, whether or not they adopt audit programs. Although environmental laws do not require a regulated facility to have an auditing program, ultimate responsibility for the environmental performance of the facility lies with top management, which therefore has a strong incentive to use reasonable means, such as environmental auditing, to secure reliable information of facility compliance status.

EPA does not intend to dictate or interfere with the environmental management practices of private or public organizations. Nor does EPA intend to mandate auditing (though in certain instances EPA may seek to include provisions for environmental auditing as part of settlement agreements, as noted below). Because environmental auditing systems have been

\footnotetext{
${ }^{2}$ See, e.g., "Current Practices in Environmental Auditing," EPA Report No. EPA-230-09-83-006, February 1984; "Annotated Bibliography on Environmental Auditing," Fifth Edition, September 1985, both available from: Regulatory Reform Staff, PM-223, EPA, 401 M Street SW, Washington, DC 20460.
} 
widely adopted on a voluntary basis in the past, and because audit quality depends to a large degree upon genuine management commitment to the program and its objectives, auditing should remain a voluntary activity.

\section{EPA Policy on Specific Environmental Auditing Issues}

\section{A. Agency Requests for Audit Reports}

EPA has broad statutory authority to request relevant information on the environmental compliance status of regulated entities. However, EPA believes routine Agency requests for audit reports ${ }^{3}$ could inhibit auditing in the long run, decreasing both the quantity and quality of audits conducted. Therefore, as a matter of policy, EPA will not routinely request environmental audit reports.

EPA's authority to request an audit report, or relevant portions thereof, will be exercised on a case-by-case basis where the Agency determines it is needed to accomplish a statutory mission, or where the Government deems it to be material to a criminal investigation. EPA expects such requests to be limited, most likely focused on particular information needs rather than the entire report, and usually made where the information needed cannot be obtained from monitoring, reporting or other data otherwise available to the Agency. Examples would likely include situations where: audits are conducted under consent decrees or other settlement agreements; a company has placed its management practices at issue by raising them as a defense; or state of mind or intent are a relevant element of inquiry, such as during a criminal investigation. This list is illustrative rather than exhaustive, since there doubtless will be other situations, not subject to prediction, in which audit reports rather than information may be required.

EPA acknowledges regulated entities' need to self-evaluate environmental performance with some measure of privacy and encourages such activity. However, audit reports may not shield monitoring, compliance, or other information that would otherwise be reportable and/or accessible to EPA, even if there is no explicit 'requirement' to generate that data. 4 Thus, this policy does not alter regulated entities' existing or future obligations to monitor, record or report information required under environmental statutes, regulations or permits, or to allow EPA access to that information. Nor does this policy alter EPA's authority to request and receive any relevant information - including that contained in audit reports under various environmental statutes (e.g., Clean Water Act section 308, Clean Air Act sections 114 and 208) or in other administrative or judicial proceedings.

\footnotetext{
${ }^{3}$ An "environmental audit report" is a written report which candidly and thoroughly presents findings from a review, conducted as part of an environmental audit as described in section II.A., of facility environmental performance and practices. An audit report is not a substitute for compliance monitoring reports or other reports or records which may be required by EPA or other regulatory agencies.
}

${ }^{4}$ See, for example, "Duties to Report or Disclose Information on the Environmental Aspects of Business Activities," Environmental Law Institute report to EPA, final report, September 1985. 
Regulated entities also should be aware that certain audit findings may by law have to be reported to government agencies. However, in addition to any such requirements, EPA encourages regulated entities to notify appropriate State or Federal ofticials of findings which suggest significant environmental or public health risks, even when not specifically required to do so.

\section{B. EPA Response to Environmental Auditing}

\section{General Policy}

EPA will not promise to forgo inspections, reduce enforcement responses, or offer other such incentives in exchange for implementation of environmental auditing or other sound environmental management practices. Indeed, a credible enforcement program provides a strong incentive for regulated entities to audit.

Regulatory agencies have an obligation to assess source compliance status independently and cannot eliminate inspections for particular firms or classes of firms. Although environmental audits may complement inspections by providing self-assessment to assure compliance, they are in no way a substitute for regulatory oversight. Moreover, certain statutes (e.g. RCRA) and Agency policies establish minimum facility inspection frequencies to which EPA will adhere.

However, EPA will continue to address environmental problems on a priority basis and will consequently inspect facilities with poor environmental records and practices more frequently. Since effective environmental auditing helps management identify and promptly correct actual or potential problems, audited facilities' environmental performance should improve. Thus, while EPA inspections of self-audited facilities will continue, to the extent that compliance performance is considered in setting inspection priorities, facilities with a good compliance history may be subject to fewer inspections.

In fashioning enforcement responses to violations, EPA policy is to take into account, on a case-by-case basis, the honest and genuine efforts of regulated entities to avoid and promptly correct violations and underlying environmental problems. When regulated entities take reasonable precautions to avoid noncompliance, expeditiously correct underlying environmental problems discovered through audits or other means, and implement measures to prevent their recurrence, EPA may exercise its discretion to consider such actions as honest and genuine efforts to assure compliance. Such consideration applies particularly when a regulated entity promptly reports violations or compliance data which otherwise were not required to be recorded or reported to EPA.

\section{Audit Provisions as Remedies in Enforcement Actions}

EPA may propose environmental auditing provisions in consent decrees and in other settlement negotiations where auditing could provide a remedy for identified problems 
and reduce the likelihood of similar problems recurring in the future. ${ }^{5}$ Environmental auditing provisions are most likely to be proposed in settlement negotiations where:

- A pattern of violations can be attributed, at least in part, to the absence or poor functioning of an environmental management system; or

- The type or nature of violations indicates a likelihood that similar noncompliance problems may exist or occur elsewhere in the facility or at other facilities operated by the regulated entity.

Through this consent decree approach and other means, EPA may consider how to encourage effective auditing by publicly owned sewage treatment works (POTWs). POTWs often have compliance problems related to operation and maintenance procedures which can be addressed effectively through the use of environmental auditing. Under its National Municipal Policy EPA already is requiring many POTWs to develop composite correction plans to identify and correct compliance problems.

\section{Environmental Auditing at Federal Facilities}

EPA encourages all federal agencies subject to environmental laws and regulations to institute environmental auditing systems to help ensure the adequacy of internal systems to achieve, maintain and monitor compliance. Environmental auditing at federal facilities can be an effective supplement to EPA and state inspections. Such federal facility environmental audit programs should be structured to promptly identify environmental problems and expenditiously develop schedules for remedial action.

To the extent feasible. EPA will provide technical assistance to help federal agencies design and initiate audit programs. Where appropriate, EPA will enter into agreements with other agencies to clarify the respective roles, responsibilities and commitments of each agency in conducting and responding to federal facility environmental audits.

With respect to inspections of self-audited facilities (see section III.B.1 above) and requests for audit reports (see section III.A above), EPA generally will respond to environmental audits by federal facilities in the same manner as it does for other regulated entities, in keeping with the spirit and intent of Executive Order 12088 and the EPA Federal Facilities Compliance Strategy (January 1984, update forthcoming in late 1986). Federal agencies should, however, be aware that the Freedom of Information Act will govern any disclosure of audit reports or audit-generated information requested from federal agencies by the public.

When federal agencies discover significant violations through an environmental audit, EPA encourages them to submit the related audit findings and remedial action plans expeditiously to the applicable EPA regional office (and responsible state agencies, where appropriate) even when not specifically required to do so. EPA will review the audit findings and action

\footnotetext{
${ }^{5}$ EPA is developing guidance for use by Agency negotiators in structuring appropriate environmental audit provisions for consent decrees and other settlement negotiations.
} 
plans and either provide written approval or negotiate a Federal Facilities Compliance Agreement. EPA will utilize the escalation procedures provided in Executive Order 12088 and the EPA Federal Facilities Compliance Strategy only when agreement between agencies cannot be reached. In any event, federal agencies are expected to report pollution abatement projects involving costs (necessary to correct problems discovered through the audit) to EPA in accordance with OMB Circular A-106. Upon request, and in appropriate circumstances, EPA will assist affected federal agencies through coordination of any public release of audit findings with approved action plans once agreement has been reached.

\section{Relationship to State or Local Regulatory Agencies}

State and local regulatory agencies have independent jurisdiction over regulated entities. EPA encourages them to adopt these or similar policies, in order to advance the use of effective environmental auditing in a consistent manner.

EPA recognizes that some states have already undertaken environmental auditing initiatives which differ somewhat from this policy. Other states also may want to develop auditing policies which accommodate their particular needs or circumstances. Nothing in this policy statement is intended to preempt or preclude states from developing other approaches to environmental auditing. EPA encourages state and local authorities to consider the basic principles which guided the Agency in developing this policy:

- Regulated entities must continue to report or record compliance information required under existing statutes or regulations, regardless of whether such information is generated by an environmental audit or contained in an audit report. Required information cannot be withheld merely because it is generated by an audit rather than by some other means.

- Regulatory agencies cannot make promises to forgo or limit enforcement action against a particular facility or class of facilities in exchange for the use of environmental auditing systems. However, such agencies may use their discretion to adjust enforcement actions on a case-by-case basis in response to honest and genuine efforts by regulated entities to assure environmental compliance.

- When setting inspection priorities regulatory agencies should focus to the extent possible on compliance performance and environmental results.

- Regulatory agencies must continue to meet minimum program requirements (e.g., minimum inspection requirements, etc.).

- Regulatory agencies should not attempt to prescribe the precise form and structure of regulated entities' environmental management or auditing programs.

An effective state/federal partnership is needed to accomplish the mutual goal of achieving and maintaining high levels of compliance with environmental laws and regulations. The greater the consistency between state or local policies and this federal response to environmental auditing, the greater the degree to which sound auditing practices might be adopted and compliance levels improve. 
Dated: June 28, 1986.

Lee M. Thomas, Administrator.

\section{Appendix-Elements of Effective Environmental Auditing Programs}

Introduction: Environmental auditing is a systematic, documented, periodic and objective review by a regulated entity of facility operations and practices related to meeting environmental requirements.

Private sector environmental audits of facilities have been conducted for several years and have taken a variety of forms, in part to accommodate unique organizational structures and circumstances. Nevertheless, effective environmental audits appear to have certain discernible elements in common with other kinds of audits. Standards for internal audits have been documented extensively. The elements outlined below draw heavily on two of these documents: "Compendium of Audit Standards" (1983, Walter Willborn, American Society for Quality Control) and "Standards for the Professional Practice of Internal Auditing" (1981, The Institute of Internal Auditors, Inc.). They also reflect Agency analyses conducted over the last several years.

Performance-oriented auditing elements are outlined here to help accomplish several objectives. A general description of features of effective, mature audit programs can help those starting audit programs, especially federal agencies and smaller businesses. These elements also indicate the attributes of auditing EPA generally considers important to ensure program effectiveness. Regulatory agencies may use these elements in negotiating environmental auditing provisions for consent decrees. Finally, these elements can help guide states and localities considering auditing initiatives.

An effective environmental auditing system will likely include the following general elements:

I. Explicit top management support for environmental auditing and commitment to follow-up on audit findings. Management support may be demonstrated by a written policy articulating upper management support for the auditing program, and for compliance with all pertinent requirements, including corporate policies and permit requirements as well as federal, state and local statutes and regulations.

Management support for the auditing program also should be demonstrated by an explicit written commitment to follow-up on audit findings to correct identified problems and prevent their recurrence.

II. An environmental auditing function independent of audited activities. The status or organizational locus of environmental auditors should be sufficient to ensure objective and unobstructed inquiry, observation and testing. Auditor objectivity should not be impaired by personal relationships, financial or other conflicts of interest, interference with free inquiry or judgment, or fear of potential retribution.

III. Adequate team staffing and auditor training. Environmental auditors should possess or have ready access to the knowledge, skills, and disciplines needed to accomplish audit objectives. Each individual auditor should comply with the company's professional standards of conduct. 
Auditors, whether full-time or part-time, should maintain their technical and analytical competence through continuing education and training.

IV. Explicit audit program objectives, scope, resources and frequency. At a minimum, audit objectives should include assessing compliance with applicable environmental laws and evaluating the adequacy of internal compliance policies, procedures and personnel training programs to ensure continued compliance.

Audits should be based on a process which provides auditors: all corporate policies, permits, and federal, state, and local regulations pertinent to the facility; and checklists or protocols addressing specific features that should be evaluated by auditors.

Explicit written audit procedures generally should be used for planning audits, establishing audit scope, examining and evaluating audit findings, communicating audit results, and following-up.

V. A process which collects, analyzes, interprets and documents information sufficient to achieve audit objectives. Information should be collected before and during an onsite visit regarding environmental compliance (1), environmental management effectiveness (2), and other matters (3) related to audit objectives and scope. This information should be sufticient, reliable, relevant and useful to provide a sound basis for audit findings and recommendations.

a. Sufficient information is factual, adequate and convincing so that a prudent, informed person would be likely to reach the same conclusions as the auditor.

b. Reliable information is the best attainable through use of appropriate audit techniques.

c. Relevant information supports audit findings and recommendations and is consistent with the objectives for the audit.

d. Useful information helps the organization meet its goals.

The audit process should include a periodic review of the reliability and integrity of this information and the means used to identify, measure, classify and report it. Audit procedures, including the testing and sampling techniques employed, should be selected in advance, to the extent practical, and expanded or altered if circumstances warrant. The process of collecting, analyzing, interpreting, and documenting information should provide reasonable assurance that audit objectivity is maintained and audit goals are met.

VI. A process which includes specific procedures to promptly prepare candid, clear and appropriate written reports on audit findings, corrective actions, and schedules for implementation.

Procedures should be in place to ensure that such information is communicated to managers, including facility and corporate management, who can evaluate the information and ensure correction of identified problems. Procedures also should be in place for determining what internal findings are reportable to state or federal agencies.

VII. A process which includes quality assurance procedures to assure the accuracy and thoroughness of environmental audits. Quality assurance may be accomplished through supervision, independent internal reviews, external reviews, or a combination of these approaches. 
Footnotes to Appendix

(1) A comprehensive assessment of compliance with federal environmental regulations requires an analysis of facility performance against numerous environmental statutes and implementing regulations. These statutes include:

Resource Conservation and Recovery Act

Federal Water Pollution Control Act

Clean Air Act

Hazardous Materials Transportation Act

Toxic Substances Control Act

Comprehensive Environmental Response, Compensation and Liability Act

Safe Drinking Water Act

Federal Insecticide, Fungicide and Rodenticide Act

Marine Protection, Research and Sanctuaries Act

Uranium Mill Tailings Radiation Control Act

In addition, state and local government are likely to have their own environmental laws. Many states have been delegated authority to administer federal programs. Many local governments' building, fire, safety and health codes also have environmental requirements relevant to an audit evaluation.

(2) An environmental audit could go well beyond the type of compliance assessment normally conducted during regulatory inspections, for example, by evaluating policies and practices, regardless of whether they are part of the environmental system or the operating and maintenance procedures. Specifically, audits can evaluate the extent to which systems or procedures:

1. Develop organizational environmental policies which: a. implement regulatory requirements; b. provide management guidance for environmental hazards not specifically addressed in regulations;

2. Train and motivate facility personnel to work in an environmentally-acceptable manner and to understand and comply with government regulations and the entity's environmental policy;

3. Communicate relevant environmental developments expeditiously to facility and other personnel;

4. Communicate effectively with government and the public regarding serious environmental incidents;

5. Require third parties working for, with or on behalf of the organization to follow its environmental procedures;

6. Make proficient personnel available at all times to carry out environmental (especially emergency) procedures; 
7. Incorporate environmental protection into written operating procedures;

8. Apply best management practices and operating procedures, including "good housekeeping" techniques;

9. Institute preventive and corrective maintenance systems to minimize actual and potential environmental harm;

10. Utilize best available process and control technologies;

11. Use most-effective sampling and monitoring techniques, test methods, recordkeeping systems or reporting protocols (beyond minimum legal requirements);

12. Evaluate causes behind any serious environmental incidents and establish procedures to avoid recurrence;

13. Exploit source reduction, recycle and reuse potential wherever practical; and

14. Substitute materials or processes to allow use of the least-hazardous substances feasible.

(3) Auditors could also assess environmental risks and uncertainties.

[FR Doc. 86-15423 Filed 7-8-86 8:45 am]

\section{BILLING CODE 6560-50-M}


APPENDIX C

BIBLIOGRAPHY 


\section{BIBLIOGRAPHY}

The Independent Technical Review team examined a number of documents that provided background information on the Uranium Mill Tailings Remedial Action (UMTRA) sites and identified the procedures and past findings of the TAC audit program.

\section{Project Management Documents}

1. Final Technical Assistance Contractor Management Plan (DOE/AL/62350-38F), September 1993.

2. UMTRA Project Office Quality Assurance Program Plan (DOE/AL/62350-76, Rev. 5), November 1993.

3. UMTRA Project Technical Assistance Contractor Quality Assurance Implementation Plan (DOE/AL/62350-72D, Rev. 0), March 1994.

4. The Uranium Mill Tailings Remedial Action (UMTRA) Project Regulatory Compliance Department Charter.

5. An unnumbered draft procedure titled TAC Regulatory Compliance Department Audit Programs.

6. Letter from Art Vollmer to Bennett Young dated May 3, 1994, titled UMTRA ES\&H Operation Envelope.

7. Letter from Linda Ulland to Roger Nelson dated January 10, 1994, titled Health and Safety Audits.

8. Uranium Mill Tailings Remedial Action Project Safety Advancement Field Effort (SAFE) Program (DOE/AL/62350-5, Rev. 1), February 1994.

9. Technical Approach Document (TAD) Checklist for review of UMTRA RAP requirements Section 17.3.2; April 29, 1988.

10. Memo from Art Vollmer to Bennett Young dated May 3, 1994; Subject: UMTRA ES\&H Operating Envelope, JEGA/UMT/0594-0228.

11. Draft DOE UMTRA Project Office ES\&H Quality Assurance Guidelines; February 7, 1994.

12. UMTRA Project Environmental, Safety, and Health Plan (UMTRA-DOE/AL-150224.0006), Revised November 1992.

13. AADITS User's Manual.

14. TRAIN Operating Instructions. 
15. UMTRA Technical Assistance Contractor Quality Assurance Program Plan (DE-AC0491AL62350, Rev. 3), June 1992.

\section{Site-Specific Documents}

1. Remedial Action Plan and Site Design for Stabilization of the Inactive Uranium Mill Tailings Sites at Rifle, Colorado, Final: Volume I-Text; Appendices $A, B$, and C (UMTRA-DOE/AL050506.0000), August 1991.

2. Remedial Action Plan for the Codisposal and Stabilization of the Monument Valley and Mexican Hat Uranium Mill Tailings at Mexican Hat, Utah (UMTRA-DOE/AL-050509-0000), February 1993.

3. Remedial Action Inspection Plan, Rifle, Colorado (MK-F-UMTRA-41, Rev. 1) January 18, 1994.

4. Remedial Action Inspection Plan, Mexican Hat, Utah/Monument Valley, Arizona (MK-FUMTRA-33).

5. Memo from R. Meyers to J. McBee dated January 13, 1993; Subject: Mexican Hat Barrier Detail Revision (JEGE/JEG/0193-0003) [NOTE: appears to be technically correct. From a QA standpoint, calculated values are not clearly distinguished from measured data. There is no way to evaluate the computer spreadsheet.]

6. Memo notification of QA surveillance at Mexican Hat and Monument Valley; May 13, 1994.

\section{Past Audit Reports}

1. Environmental Audit Report for the Rifle, Colorado, Site, June 29 - July 1, 1993.

2. Health and Safety Audit Report, Rifle, Colorado, Site (DOE/AL/62350-42), June 1993.

3. Radiological, Health and Safety, and Occurrence Reporting System Audit Report, Rifle, Colorado (DOE/AL/62350-86), November 1993.

4. Memo from Linda Ulland to Bennett Young dated January 1994; Subject: Health and Safety Audit Report, Gunnison, Colorado (JEGA/UMT/0194-0736).

5. Letter from John Isham to Frank Bosiljevac dated October 4-7, 1993; Subject: MK-Ferguson Response to Supplemental Audit Response Questions, Gunnison, Colorado, Audit.

6. Memo from Frank Bosiljevac to Robert Lawrence; UMTRA Review of MK-Ferguson's Gunnison, Colorado, ES\&H Audit Response (October 4-7, 1993) to (sic) For Closure or Further Action; (no file code) April 6, 1994.

7. Memo from Linda Ulland to Bennett Young dated November 1, 1993; Subject: Environmental Audit Report for the Mexican Hat, Utah, and Monument Valley, Arizona, UMTRA Project Sites (JEGA/UMT/1193-0677). 
8. Memo from Linda Ulland to Bennett Young dated June 17, 1994; Subject: Environmental Audit Report For Ambrosia Lake, New Mexico (JEGA/UMT/0693-0313).

9. Report of Quality Assurance Audit of Morrison-Knudson Environmental Services, Inc., San Francisco, CA, October 25-27, 1993 (DOE/AL/62350-91).

10. Report of Quality Assurance Surveillance of MK-Ferguson Company Remedial Action Construction, UMTRA Project, Mexican Hat, Utah, Monument Valley, Arizona (DOE/AL/62350-82), October 15, 1993.

11. Report of Quality Assurance Surveillance of MK-Ferguson Company Remedial Action Construction, UMTRA Project, Mexican Hat, Utah, Monument Valley, Arizona (DOE/AL/62350-82), April 14, 1993.

12. Radiological Audit of Remedial Action Activities at the Processing Site Rifle, Colorado; (DOE/AL/62350-39F), July 1993.

TAC Standard Operating Procedures - [Based on the JEG Albuquerque Operations Manual Procedures Status List dated May 6, 1994]

1. Section 0.1: Albuquerque Operations Office Policies and Procedures; January 3, 1990.

2. Section 0.2: UMTRA TAC Organization Chart; August 27, 1993.

3. Section 0.3: UMTRA TAC Project Position Responsibilities; July 23, 1993.

4. Section 7.1: UMTRA Project Environmental Health and Safety Plan; May 1, 1989 [Delete as an SOP: This will remain as an UMTRA Project document. It will be updated and SOP 7.3.1 will be incorporated into it.]

5. Section 7.2: TAC Environmental Health and Safety Plan; December 2, 1988 [Delete as an SOP: This should remain an UMTRA project document. It will be updated and SOP 7.3.2 will be incorporated into it.]

6. Section 7.3.1: Occupational Safety and Health Complaints; October 5, 1990 [Delete as an SOP: it will be incorporated into the UMTRA Project ES\&H Plan and updated.]

7. Section 7.3.2: Occupational Safety and Health Complaints for TAC Subcontractors; April 29, 1991 [Delete. This SOP belongs with the TAC ES\&H Plan and should be incorporated into it.]

8. Section 8.2.1: Technical Data Acquisition and Quality Assurance; September 30, 1988.

9. Section 9.1: Quality Assurance Program Plan; September 18, 1992.

10. Section 9.2.1: Qualifications of Audit Personnel; January 4, 1989.

11. Section 9.2.2: Quality Audits; January 4, 1989. 
12. Section 9.2.3: Training; June 8, 1993.

13. Section 9.2.4: In-Process Construction Surveillance; January 4, 1989.

14. Section 9.2.9: UMTRA Audit/Surveillance Activity And Remedial Action Inspection Plan Tracking System; June 12, 1989 [Delete. This SOP explains how to use a program that no longer exists. AADITS is the new program and there is already a desktop user's guide.]

15. Section 9.2.11: Inspection of Subcontractors' Operations; November 14, 1988.

16. Section 10.1.1: Implementation of ALARA Program; February 26, 1990.

17. Section 10.7.1: Tac Radiological Audits; March 10, 1993.

18. Section 10.10.1: Quality Control Checks of the Remedial Action Contractor's Use of the Opposed Crystal System; April 18, 1991.

19. Section 11.3.1: Environmental Audits; November 18, 1992.

20. Section 14.3.4: Piezocone Testing; May 15, 1987.

21. Section 14.4.1: Soil and Rock Core Borehole and Test Pit Logging; April 29, 1988.

22. Section 14.5.1: Procedures for Handling and Shipping of Uncontaminated Geotechnical Samples; October 27, 1992.

23. Section 15.2.1: Technical Representative for Soils Laboratory Subcontractors; March 31, 1987.

24. Section 16.1.12: Method for Measuring Sub-Surface Moisture and Density Using a CPN 501 DR Depthprobe; January 11, 1993.

25. Section 17.2.1: Conceptual Design; April 29, 1988.

26. [no identifier]: Peer Review; November 18. 1988.

27. [no identifier]: FTR (Field Technical Representative) Daily Diary: June 3, 1992.

\section{ASTM Standards}

1. ASTM D 1452-80: Standard Practice for Soil Investigation by Auger Borings.

2. ASTM D 4643-93: Standard Test Method for Determination of Water/Moisture Content of Soil by the Microwave Oven Method.

3. ASTM D 4220-89: Standard Practice for Preserving and Transporting Soil Samples.

4. ASTM D 2487-93: Standard Classification of Soils for Engineering Purposes. 
5. ASTM D 3441-86: Standard Test Method for Deep, Quasi-Static, Cone and Friction Cone Penetration Tests of Soil. 